$$
\text { المجلد (r). العدد (1 (). الجزء الثاني. مارس } 17 \text { ـ r. ص ص 1 - عץ }
$$

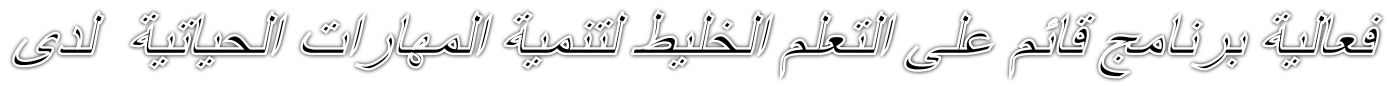

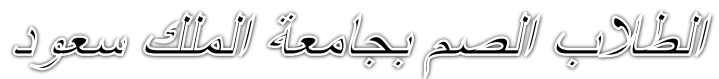

$$
\begin{aligned}
& \text { إعداد } \\
& \text { د/ خــالـــ محمد النجــار } \\
& \text { أستاذ مساعد - عمادة السنة التحضيرية }
\end{aligned}
$$

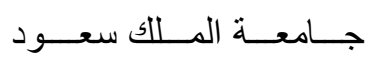

DOI: 10.12816/0029013 
إعداد

$$
\begin{aligned}
& \text { فعالية برنامج قائم على التعلم الخلبط لتنمية المهارات الحياتبة }
\end{aligned}
$$

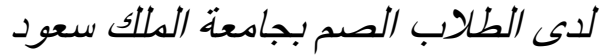

د/ خــالـــ محمـد النجــار (")

$$
\text { ملخ مان }
$$

استهدفت الدراسة فعالية برنامج قائم على التعلم الخليط لتتمية المهارات الحياتية لدى (ع ب)

طالبًا بمشروع تعليم الصم وضعاف السمع بجامعة الملك سعود. حيث كثفت العديد من الدراسات وجود حاجات عديدة وملحه لإعداد برامج فعالة في تعليم الصم وضعاف السمع بعد وصولهم للمرحلة الجامعية. ودمجهم مع أقرانهم. ووجود الندرة في هذه البرامج المقدمة لهم أسوة بالطلاب السامعين بالمملكة العربية السعودية. وكثفت الدراسة عن فعالية البرنامج المقترح لتنمية المهارات الحياتية للطلاب الصم. ضرورة وضع برامج تعليمية بم يتتاسب مع خصائص الصم بجامعة الملك سعود. تطوير المقررات التعليمية بالجامعة بما يتوافق مع طبيعة الطلاب الصم. الكلمات المفتاحية : برنامج - التعلم الخليط - المهارات الحياتية- الصم.

Title: The effectiveness of a program based on a mixture of learning to the development of life skills for deaf students at King Saud University

The study targeted the effectiveness of a program based on learning the mixture to the development of life skills (24) a student project education of the deaf and hard of hearing, King Saud University, where he revealed many of the studies that there are many needs and the urgent need to develop effective programs in the education of the deaf and hard of hearing after their arrival undergraduate, and integrating them with their peers and the existence of scarcity in these programs provided to them just like the students who heard the Kingdom of Saudi Arabia, the study revealed the effectiveness of the proposed program for the development of life skills for students deaf, the need to develop educational programs including commensurate with the deaf properties at King Saud University, the development of courses from the university in accordance with the nature of deaf students .

Key words: Program - Blended Learning - skills Life - Deaf 


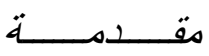

عالمنـا المعاصـر يتطلب منـا إعداد أجيالنـا بطريقـة تربويـة. وتعليميـة تواكب التطـور الحديث؛ ليتسنى لهم فهم. واستيعاب ما يدور حولهم. ومعرفة مـا ينتظرهم فى المستقبل من توقعات وتغيرات تؤثر فى مسيرة حياتهم مدا يتطلب ضـرورة تطوير مفهوم التعليم. وأهدافهـ. ومناهجه الدراسية؛ لمواجهة هذه التحديات. والمتطلبات؛ لذا سارعت العديد من الدول المتقدمة بتطوير التعليم بكافـة أنواعـه المبنـي على تهيئة المتعلم للتفسير وتحليل والتي بدورها تحسـن عادات العقل للمتعلم. وفي ظل عصر المعلوماتيـة والإنترنت كانت الحاجـة لاستخدام كل مـا يتيحـه العصر من أدوات وتقنيات وبرامج تعليميـة من قبل الطلاب وتثـيعهم من قبل المعلم

$$
\text { ومن هنا جاءت الضرورة لاستخدام التعلم الخليط (زائد. } 10 \text { • ب). }
$$

ولقد صار من الضروري استحداث وابتكار أساليب جديدة في التدريس فالتحدي العلمي والتكنولوجي الذى فرض نفسـة على العالم اليوم يتطلب من الافراد أن يكتسبوا مهارات وقدرات جديدة متتوعة حتى يجدوا مكانهم في القرن الحادي والعشرين. ويتميز عصرنا الحالي بالمعرفة وثورة الاتصالات وتبادل المعلومات بتقنياتها المختلفة ( الغرباوي.0 1 • ؟). ويعد التعليم الخليط مكـلاً لأسـاليب التعليم التربويـة العادية. ويعتبر هذا التعليم رافدًا كبيرًا للتعليم الجامعي التقليدي؛ الذي يعتمد على المحاضرة. إذ إن تقنية المعلومات ليست هدفاً أو غاية بحد ذاتها. بل هي وسيلة؛ لتوصيل المعرفة. وتحقيق الأغراض المعروفة من التعليم والتربية.

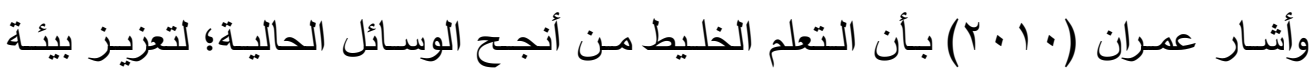
تعليميـة ثريـة. تعمل على تعزيز مسئولية البحث عن المعلومـات وصياغتها ممـا ينمي مهارات التعلم الذاتي لديهم. ووضـح سـلامة (0 . ․ r) أن التعلم الخليط هو أحد أهم المصطلحات الحديثة في مجال تكنولوجيا المعلومات في التربية ـ ويقصد بالتعلم الخليط "مزج أو خلط أدوار" المعلم التقليدية في الفصول الدراسية التقليدية مع الفصول الافتراضية. والمعلم الاككتروني. أي أنه تعلم يجمع بين التعلم التقليدي. والتعلم الالكتروني. 


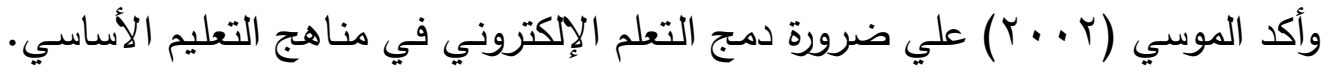

لما له من أهية في إعداد المتعلم لمواجهة متطلبات الحياة العملية بكل أوجهها. والتي أصبحت تعتمد بشكل أو بآخر علي تقنية المعلومات. وطبيعتها المتغيرة بسرعة.

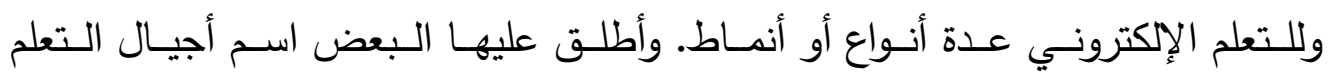

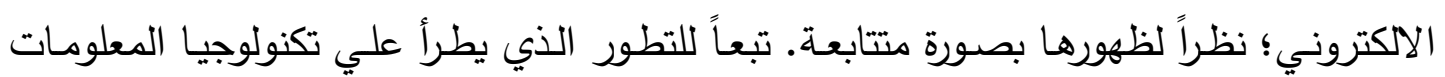
والاتصـالات. ومنها : التعلم الإككتروني المعتمد علي التقنيات (من خـلال التلفزيون وأشرطة الفيديو والأثرطة السمعية ). والتعلم الإكتروني المعتمد علي الكمبيوتر ( غير المعتمد علي الإنترنت ). والتعلم الإلكتروني المعتمد علي الإنترنت (التعلم المباشر (online learning).

و Mobile Learning التعلم الإلكتروني المعتمد علي تتنية التليفون المحمول (الموبايل)

والتعلم الخليط Blended Learning.

ومـن خـلال العديـد مـن البحـوث. والدراسـات التي تتاولت موضـوع الدراسـة. كدراسـة

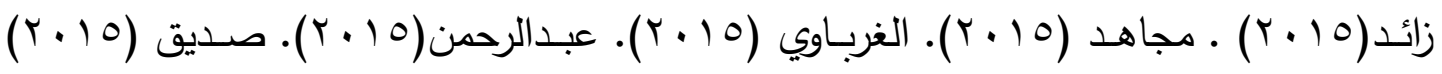

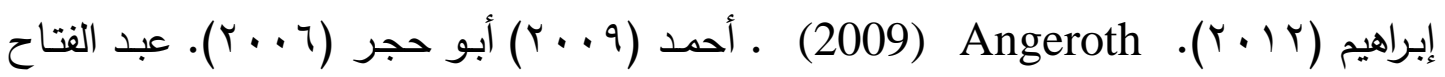

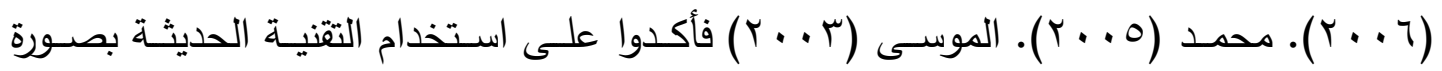
ملائمة في عملية التعليم. والتعلم تؤدي إلى تحسين عملية التعليم. وتزيد من تحصيل الطلاب للمعرفة. وتتمي -لديهر - مهارات التفكير . كما أنها توفر بيئة تعليمية تفاعلية مناسبة للطلاب. وتبادل الآراء. والخبرات. ولهذا نبعت فكرة هذه الدراسـة المتمثلة في فعالية برنامج قائم على لهى التعلم الخليط لتتمية المهارات الحياتية للى الطلاب الصم بجامعة الملك سعود .

مشكلــة الـــراســة انطلاقاً من منـاداة كثير من الحركات الإصـلاحية في مجال تطوير منـاهج الخاصـة بتعليم الصم باعتبار التتنية بُعدًا رئيسًا في تعديل المناهج. ومساعدة المعلمين والطلاب الصم. فالعديد من الدراسات السابقة والبحوث نادت بتجديد المناهج. ووضع البرامج المتعددة في ضوء احتياجـات وخصـائص الصـم وضـعاف السـمع. وسـعت وزارة التربيـة والتعليم بالمملكة العربيـة 
السعودية نحو دمـج التقنية بالتعليم وجعل التقنية جزءًا لا يتجزأ من المنهج والمواقف التعليميـة؛ حيث أخذت بفكرة التعلم القائم على الأسـاليب الحديثة والفعالة وتطبيقـه في الميدان التربوي. وذلك مـن خـلال عدة مشـاريح. منهـا: مشـروع الكتب الإكترونيـة التعليميـة"( E-BOOK ). ومشروع المختبرات المحوسبة. ومشروع مراكز مصـادر التعلم الرقميـة. والفصول الذكية (وزارة

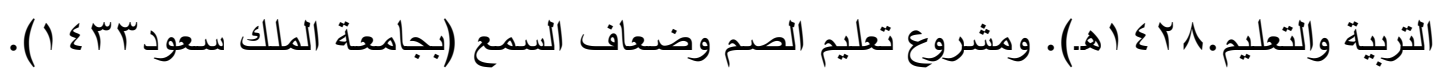

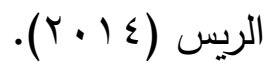

ومن خـلال هذا الاهتمام يمكن تحديد مشكلة الدراسـة في وجود حاجات عديدة لإعداد بـرامج فعالـة في تعليم الصـم وضـعاف السـمع بعد وصـولهم للمرحلـة الجامعيـة. ودمجهم مـع أقرانهم. ووجود الندرة في هذه البرامج المقدمـة لهم أسـوة بـالطلاب السـامعين. سواء بالمملكة العربيـة السـعودية. أو الجامعـات بالـدول العربيـة؛ التى لـم يلتحق بهـا الصـم وضـعاف السـمع. وللتصدى لهذه المشكلة سيقوم الباحث بإعداد برنامج قائم على التعلم الخليط لتنميـة المهارات الحياتية لـى الطـلاب الصـم بجامعـة الملك سعود. ومنـه يمكن الإجابـة عن التسـاؤل الرئيس التالى :

ما فعالية برنامج قائم على التعلم الخليط لتنمية المهارات الحياتية لاى الطلاب الصـ

بجامعة الملك سعود؟

$$
\text { أهـــداف الــدر/ســة }
$$

استهدفت الدراسة الحالية ما يلي:

• تقديم أساس نظري للتعلم الخليط لتتمية المهارات الحياتية لدى الطلاب الصم بجامعة الملك سعود.

إعداد برنـامج لتتميـة المهـارات الحياتيـة المتقدمـة لدى الطـلاب الصـم بجامعـة الملكك

التعرف على فعاليـة البرنـامج القائم على التعلم الخليط لتنميـة المهارات الحياتيـة لدى الطلاب الصم بجامعة الملك سعود. 


$$
\text { الحــدود الــــر اســة }
$$

تم اختيـار عينـة الدراسـة من الطـلاب الصـم بكليـة التربيـة جامعـة الملك سعود وعددهم

$$
\begin{aligned}
& \text { ( ؟ ب). (مشروع تعليم الصم). } \\
& \text { الحدود الموضـوعيـة }
\end{aligned}
$$

اقتصرت الدراسة على تنمية بعض المهارات الحياتية المناسبة واللازمة ومنها:(مهارات

$$
\text { الاعتمـاد على النفس - مهارات التواصـل الاجتمـاعي - مهارات الحوار - مهارات اسـخدام }
$$

الحاسب الآلي والإنترنت). والتي يمكن إكسابها للطلاب للصم من خلال خلط التقنية.

$$
\text { الحسدود المكانية }
$$

اقتصرت عينة الدراسة من الطلاب الصم بكلية التربية جامعة الملك سعود.

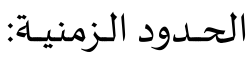

تم تتفيذ الدراسـة بعد الانتهاء من الإجراءات اللازمة لبناء البرنامج المقترح خلال العام

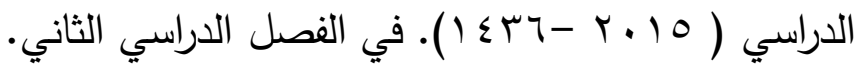

$$
\begin{aligned}
& \text { أهمبـة الــدر/ســـة: } \\
& \text { استمدت الدراسة أهميتها من الاعتبارات التالية: }
\end{aligned}
$$

• تسهم في وضع خلفية نظرية عن استخدام التقنية الحديثة؛ لتنمية المهارات الحياتية للطلاب الصم بجامعة الملك سعود. الأمر الذي يقدم للمهتمين والقائمين على إعداد وتعليم. وتدريب الصم إطارًا نظريًا قد يساعدهم في تطوير برامج أخرى تفيد الصم خاصـة بعد محاولة الدمج

$$
\text { في البيئة الجامعية. }
$$

ه تقدم للمسئولين عن تعليم الصم في التعليم العالي برنامجاً متكاملاً؛ لتدريب الطلاب الصم

من خلال التقنية الحديثة؛ لتمية المهارات الحياتية لديهم. ومزج وسائل التعلم الحديثة . تزويد أعضاء هيئة التدريس القائمين بتدريس مقررات المناهج وطرق التدري؛ للتواصل مع الصم في البيئة الجامعية (كلية التربية- السنة التأهيلية - السنة التحضيرية). 


\section{البرنامج: Program}

عبـارة عـن مجموعـة مـن المهارات والمواقف المنظمـة متعلقـة بموضـوع الدراسـة وفقق

أهداف ووسـائل تعليميـة وتدريبات خاصـة وأسـاليب تقويم معينـة. ممـا يؤدى إلى مرور الطـلاب بخبرات تعليمية محددة تساعدهم لاكتساب مهارات الحياة اللازمة لديهم (إعداد الباحث).

\section{التعلم الخليط: Blended Learning}

هو نظام قائم على استخدام التقنية الحديثة في التدريس دون التخلي عن الواقع التعليمي المعتاد. وحضور الطلاب في غرفـة الصف. ويتم التركيز على التفاعل المباشـر داخل غرفـة الصف عن طريق استخدام آليات الاتصال الحديثة: كالحاسوب. والشبكات. والإنترنت (إعداد (الباحث).

\section{Life skills}

مجموعة من المهارات المختلفة تتناول بعض جوانب شخصية الطالب الأصم. وتتمثّل في بعض جوانب التعلم. وتهدف إلى مسـاعدة الفرد على التكيف مـع الحياة. وتوظيف الفرد لمهاراته وقدراته المتعددة في مواقف الحياة المختلفة. التى يحتاج إليها(إعداد الباحث).

الصـم: Deaf

هم الأشخاص الذين لديهم نقص وقصور في حاسـة السمع. وغير قادرين على الكلام المنطـوق. ويحتاجون إلى اسـخدام الوسـائل المعينـة. والطـرق الخاصـة في التعليم والتواصـل. وينعكس ذلك على أدائهم التعليمي. وهم من المنتسبين لمشروع تعليم الصم بكلية التربية جامعة الملك سعود (إعداد الباحث).

$$
\text { الإطـــار النظـــري والــراسـات السـابقــة }
$$

يعد الإطـار النظـري مصـدراً فكريـاً ومعرفيـاً لموضـوع الدراسـة على مستوى المجـالات 
مـع نهايـة التسعينيات مـن القرن الماضـي بـدأت الموجـة الأولـى فيمـا يسـى بـالتعلم الإكتروني" E-Learning " • وهذه الموجة كانت تركز على إدخال التكنولوجيات المتطورة في العمل التدريسي. وتحويل الفصول التقليدية إلى فصول افتراضية Virtual Classrooms عن

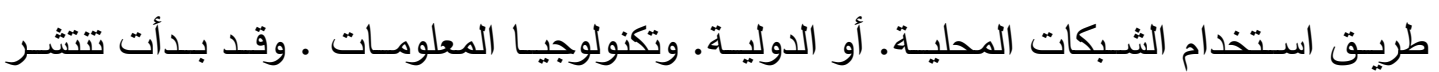
مصطلحات التعلم الالكتروني. مثل: التعلم على الخط Online learning. والتعلم عبر الثبكة Web based learning و والتعلم الرقمي Digitally learning ـ والتعلم عبر مؤتمرات الفيديو Video Conferences. وغير ذلك من مسميات (سلامة. ه... (ץ). من هنا ظهر مفهوم التعلم الخليط Blended Learning كتطور طبيعي للتعلم الإلكتروني. فهذا النوع من التعلم يجمع بين التعلم الإلكتروني. والتعلم التقليدي الصفي العادي؛ فهو تعلم لا يلغي التعلم الإلكترونسي ولا التعلم التقليدي. إنها مزيج مـن الاثثين معًا لا نلغي التطور التكنولوجي ولكن نستخدمه بشكل وظيفي في فصولنا العادية. أو في المعامل الدراسية . وتشير العديد من الدراسات إلى أهمية التعلم الخليط في تحسين العملية التعليمية. وتوفير بيئة تعليمية تفاعلية متعددة المصادر . بالإضـافة إلى المساعدة على نشر التقنية الحديثة في

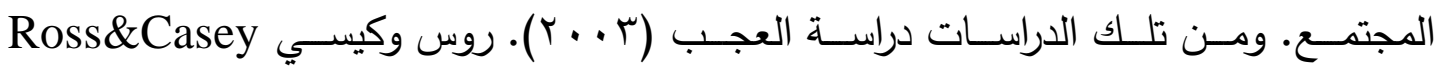

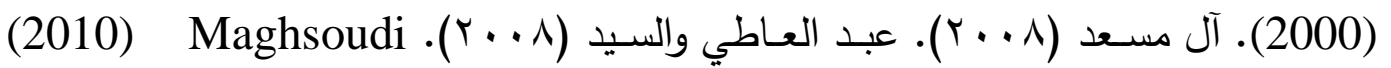
وزائدا(0 ( ب ). كما توصل كلاً من لارسون وسونق Larson\&Sung (2009). في دراستهما حول مقارنـة أداء الطلاب الذين درسوا من خلال الإنترنت مقابل الذين درسوا بالتعلم المدمج. إلى أنه لا يوجد اختلاف كبير بين الطريقتين في الفاعلية والارتياح لطريقة التعليم. ويرى عدد من التربويين والخبراء. أن التعليم المتمـازج. أو التعليم بالاعتمـاد على التقنيـة

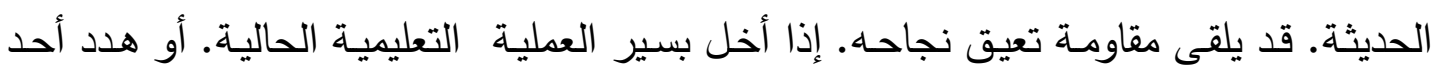
طرفيها: المعلم. والمتعلم. وهما يمثلان المكونـات الأساسية. إضـافة إلى المنـاهج التعليميـة.

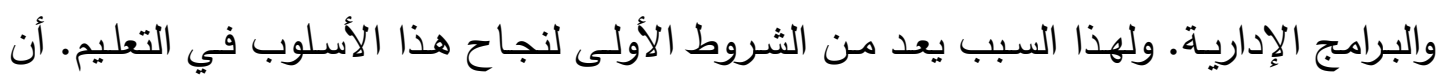


يكون مكمـلاً لأسـاليب التعليم العادية. ولكي يتم ذلك لا بد أن يكون المعلم قادرًا على استخدام تقنيات التعليم الحديثة. واستخدام الوسائل المختلفة للاتصال. كما يجب أن تتوفر لدى الطالب المهارات الخاصـة باستخدام الحاسب الآلي والانترنت والبريد الاكتروني. وتوفير البنية التحتية؛ التي تتمثل في إعداد الكوادر البشرية المدربـة. وتوفير خطوط الاتصالات المطلوبة التي تساعد على نقل هذا التعليم إلى غرف الصفوف. إضـافة إلى توفير البرمجيات والأجهزة اللازمة لهذا النوع من التعليم. وإن تطبيق مناهج وطرق التعليم المتمازج يحتاج إلى تحقيق التصور التالي: توفير مختبرات الحواسب الآلية. ووضع شبكات المعلومات المحلية والعالمية في متتاول الطالب .

تزويــ المعلم والمتعلم بالمهارات الضـرورية؛ لاسـتخدام الوسـائط المتعددة. ومـن خـلال توفير الدورات التدربيية اللازمة. توفير المناهج التعليمية المناسبة لهذا الثكل من التعليم. أن يصبح المعلمـون قادة ومرشـدين؛ لتعليم طلابهـم مـن خـلال اسـتخدامهم للحواسـب وتطبيقاتها. وشـبكات المعلومـات المحليـة والعالميـة. وإنتـاج المـواد التعليميـة المناسـبة والمتتوعة للتدريس (شوملي.0 . . ب). Yoon (2007).

traditional والتعلم الخلـيط يجمع بـين فوائـد التـدريب التقليدي الموجـهـ بـالمعلم instructor led training Encyclopedia of （البرنـامج الأمثـل. وبـين الثـكل التـالي كوصـفة للتـعلم المـزيتج .(2005) Rossett.(2008) (Educational technology ويرى كثير من التربوين أن التعلم الخليط من أهم أساليب التعلم الحديثة؛ التي تتميز بعدة خصائص ومزايا. تتمثل في: الفاعلية في تحقيق الأهداف. وتعزيز المشاركة الإيجابية Gray (2006). وكما أشار الغامدي (v . . . Abraham (2007) إلى أن التعلم المدمج يساعد في توفير المرونة للمتعمين. وذلك من خلال تقديم العديد من الفرص للتعلم بطرق مختلفة. كما يركز على أن يكون التعلم بطريقة تفاعلية. وليس بالتلقين. 


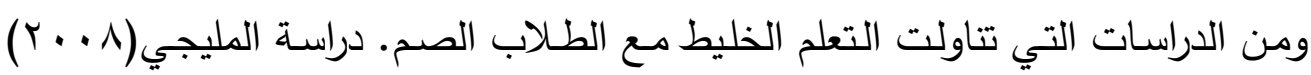

والتي سعت إلى تصميم بيئة تعلم فعالة. واستراتيجيات تعليمية معاصرة للتلاميذ ذوي الإعاقات السمعية والبصرية؛ حيث سعى إلى توظيف بعض الوسائط التعليمية والتكنولوجيا المساعدة في تدريب التلاميذ ذوى الإعاقة السمعية .

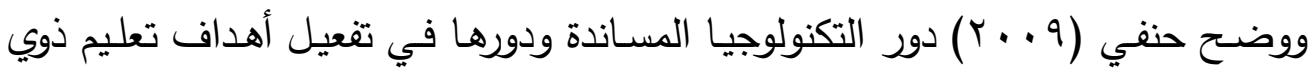

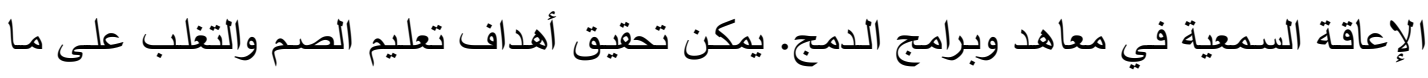
تعانيه تلك الفئة من مشكلات إذا تم توظيف التكنولوجيا المساندة في العملية التعليمية. وتدريب

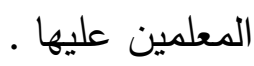

ووضع إبراهيم يونس (9 . . r) أسس برمجية تعليمية لإكساب طلاب ذوى الاحتياجات الخاصـة( المعاقين سمعياً) بعض مهارات تصميم العروض التقديمية وأثر ذلك على تواصلهم

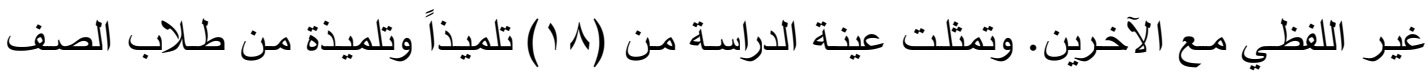
الثاني بمدرسة الأمل بدمياط. أظهرت الدراسـة عدة نتائج من أهمها فاعلية البرمجية المقترحة

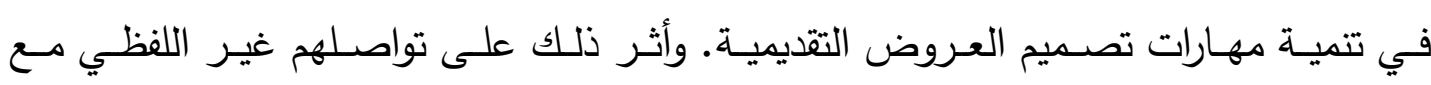
الآخرين.

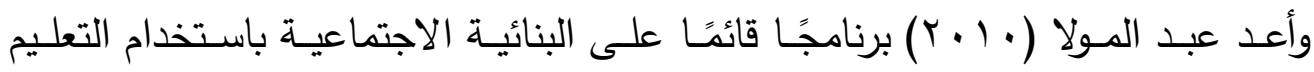
الخليط في تـريس الدراسـات الاجتماعيـة على تتميـة الدفـاهيم الجغرافيـة. والتقكيـر البصـري والمهارات الحياتية لاى التلاميذ الصم بالحلقة الإعدادية. وكانت أهم نتائج الدراسة وجود فرق دال إحصائيًا بين متوسط درجات التلاميذ مجموعة الدراسة قبل دراسة باستخدام التعليم الخليط

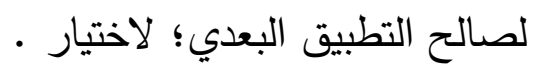
وكثف الصقير (1) ( ب) أثر استخدام برنامج وسائل متعددة في تتميـة بعض مفاهيم

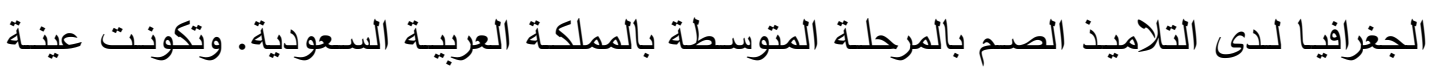

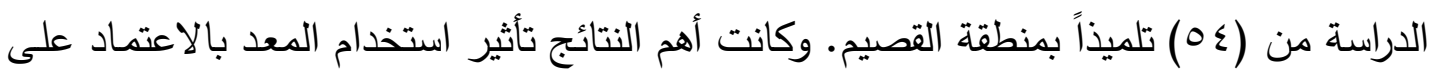
مدخل الوسائل المتعددة. ومـا بها من مؤثرات نصية وصورية. ذات الخصائص المميزة تلك 
النوعية من البرامج التفاعلية. وإثارة الاهتمام ومسـاعدة المتعلمين - عينـة الدراسـة- على إتقان بعض المفاهيم الجغرافية. وزيادة معدلات التعلم. والاكتساب لديهم.

وساهمت دراسة الغرباوي(0 ( ب ب) ببرنامج قائم على التعليم المدمج في تتمية المهارات

الحياتية وتقدير الذات لدى الطلاب الصم والبكم والتساؤلات التي تطرح نفسها ا هي الاجراءات التي تمكن الطلاب من تتميـة المهارات الحياتية الاساسية الى تتناسب مـع الطلاب الصـم في صورة برنـامج تعليمي مقترح ينتمى المهارات الحياتية التي يحتاجونها في حياتهم اليومية والتي تـؤثر عليهم وتسـاعدهم على اكتسـاب مفـاهيم ايجابيـة اتجـاه ذاتهم وتتميها. شخصية المعـاق سمعيا ماهي الا محصلة للتفاعل بين ذاته ككائن ذي اعاقة والعوامل البيئية الاجتماعية الاسرية الذى ينتمى اليها فالطفل المعاق سمعيا يكون أداؤه وطريقة تصرفاته وحرمانه من استخدام اللغة تجعله يبدو غريبا ومختلف عن الاخرين. اذا ما قورن بالطفل العادي وقد يعمل هذا الشعور بالاختلاف على التأثير على تقدير الذات لدى الطفل المعاق سمعيًا مما يشجعه على الاتجاه الى العزلة والابتعاد عن نظرات الاستغراب والدهشة او الرثاء التي قد يبديها الاخرون تجاهه.

مما سبق من نتائج البحوث والاراسات السابقة توصلت الدراسة الحالية إلى ما يلى : • أوضحت نتائج البحوث والدراسـات أثر استخدام التعلم الخليط مـع الطلاب الصم في تنمية المهارات الحياتية وخاصة بالمهارات المتقدمة. • أكدت النتائج على عدم وجود تعارض بين نتائج جميع الدراسات التى أجريت باستخدام التعلم الخليط.

أثتبت النتائج الى زيادة دوافع الطـلاب وتغيرهـا ناحية التعلم. وجعله يسير في العمليـة التعليمية بسهولة ويسر مما أدى إلى استيعابه وإدراكه للحقائق والتعلم. أثبتتات النتائج تحقيـق فعاليـة التعلم الخليط لإكسـاب الطـلاب الصـم بعض المهارات التعليمية وزيادة تواصلهم غير اللفظي مع الآخرين. 


\section{ثانيًا: المهارات الحياتية Life Skills:}

تعتبر المهارات الحياتية من أهم المهارات؛ التي تمثل ضرورة حتمية لجميع الأفراد في

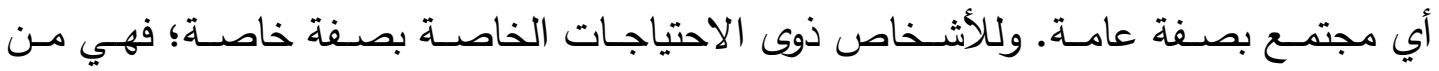

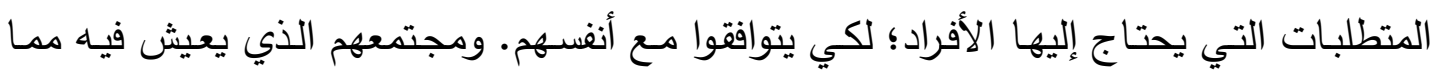
يساعدهم على حل مشكلاتهم اليومية. والتقاعل مع مواقف الحياة المختلفة.

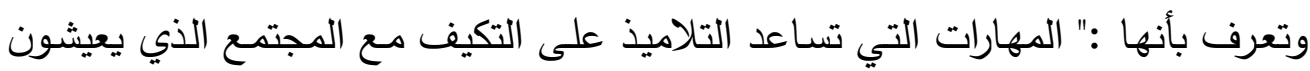
فيـه. وتركز على النمو اللغوي. والطعـام. وارتداء الملابس. والقدرة على تحمل المسئولية.

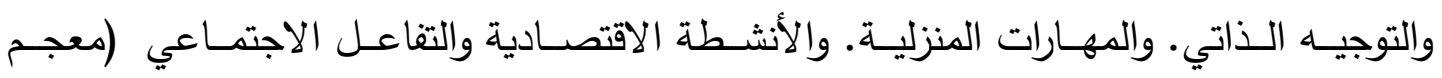
المصطلحات التربوية. r. ب. ب).

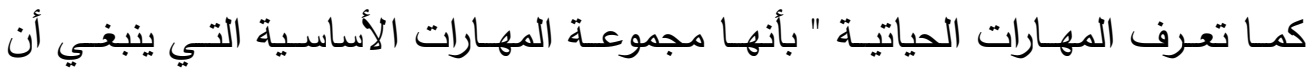
تتضمنها المناهج وتساعد التلميذ على إدارة حياته. والتعايش مـع منطلباتها. والتعامل بإيجابية

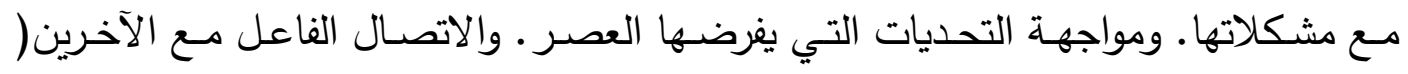

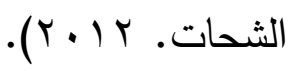

ومن الممكن الاستفادة من المهارات الحياتية للطلاب الصم؛ التي تثير إليها البحوث العلمية فيما ما يلي: ومن اليخد

تتمية بعض خصائص الثخصية. مثل : الاتصال ـ والتعاون مع الآخرين. تزويده بالمعلومات والخبرات المتعلقة بإدارة المواقف الحياتية اليومية. الطلاعه على التتنيات الحديثة. والمراجع العلمية في البحث والتجريب؛ لتتمية مهارة التعليم الذاتي. إكسابه اتجاهات ومهارات عملية إيجابية عن طريق إقامـة علاقات أسرية واجتماعية طيبة تتعكس إيجابًا على التلاحم بين فئات المجتمع المختلفة.

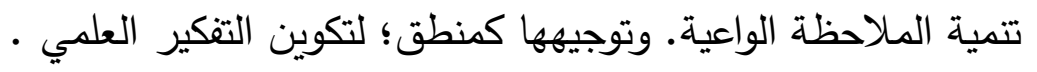
تتمية الاتجاهات الإيجابية نحو ترشيد الاستهلاك في مجالات الحياة المختلفة. تشجيعه علي ممارسة بعض المناشط الضرورية؛ لتوفير الأمن والسلامة في بيئته .

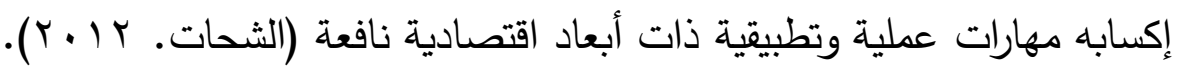




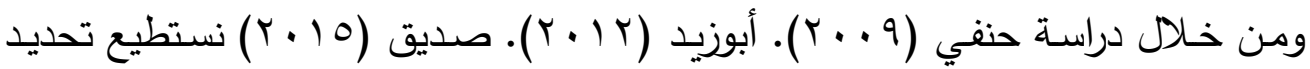
أهمية المهارات الحياتية للطلاب الصم من خلال ما يلي:

تحقيق التكامل بين المدرسة والمجتمع من خلال ربط حاجات المتعلمين ومواقف الحياة

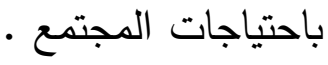

تكسب المتعلم خبرة مباشـرة. وذلك عن طريق التفاعل المباشـر بالأثـاص والظواهر الحياتيـة ـ ممـا يجعلهه قادراً على مواجهة مواقف الحياة المختلفة. والقدرة على التغلب على المشكلات. والسعي في حلها. تكسب المتعلم القدرة على إعمال العقل. وتوظيفه في ممارسة عمليات التفكير المتنوعة. تجعل المتعلم قادراً على ممارسـة الأنشطة. والعلاقات الاجتماعية بشتى أنواعها بشكل أفضل من خلال امتلاكه لمهارات التواصل المناسبة . تعطي للتعلّم معنًا. وتضفي عليه وضوحاً وواقعية مما يمكّن المتعلم من إدراك العلاقة بين ما يدرسه في غرفة الصف. وما يواجهه من ظواهر وأحداث . تسـعى إلى تتميـة روح المواطنـة لـى المتعلم. والاعتزاز بثقافـة بلده. وذلك مـن خـلال التعرف على المنجزات الوطنية في جميع المجالات. وكذلك معرفة الأنظمة والقوانين التي تساعده على العيش برفاهية واطمئنان ومـن الدراسـات التي تناولت دراسـة المهارات الحياتيـة لـدي الصـم. دراسـة ماجسـودي وآخرون (· ( • ( ) استهدفت تقصّي أثر اكتساب المهارات الحياتية من خلال روح الفكاهة على ارتقاع معدلات التكيف الاجتماعي للى طالبات المدارس العليا. وقد استخدمت الدراسـة المنهج شـبه التجريبـي. وقـد أثبتـت الدراسـة مقيــاس المهـارات الحياتيـة واختبـار معـدلات التكيـف الاجتماعي. وقد أظهرت النتائج فعالية المهارات الحياتية من خلال الروح الفكاهية. كما أوصت الدراسة بضرورة استخدام المهارات الحياتية في رفع معدلات التكيف الاجتماعي. وفحص كيتلار وآخرون Ketelaar. et.. al (r ( • r) مستويات الكفاءة الاجتماعية. والسلوك العاطفى لدى الأطفال زارعي القوقعة. ومقارنتهم بالأطفال السـامعين واعتمدت النتائج 
على تقـارير الآبـاء. وملاحظـاتهم بالإضـافة إلى أن مستويات الكفـاءة الاجتماعيـة والسـلوك التعاطفى. كانت أقل لاى زارعي القوقعة. كما أن السلوك التعاطفى منبئاً بالكفاءة الاجتماعية. وقد أشارت النتائج ضرورة مراعاة ذلك. ووضع برامج إعادة التأهيل زارعي القوقعة.

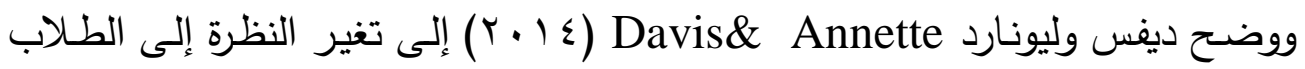
الصم. وضعاف السمع من خلال تدريبهم فى مركز الأبحاث والتدريب للصم بولاية أوريغون الغربية على بطاريات الكفاءة. وتدعيم طرق جيدة للتنكير والتعامل مـع الآخرين فى مرحلـة انتقالية. وهى المراهقة التي تعد من من أهم المراحل التى يتجه فيها الصم إلى النجاح فى العمل والبحثث عن وظيفة. معتمدين على وسـائل تكنولوجيـة مسـاعدة؛ لفهم حقوقهم. ومـن خـلال برنامج الكفاءة (TCB). هدفت إلى قياس مهارات الانتقال من المرحلة المراهقة فى الدرسـة الثانويـة إلى مرحلـة دخول التدريب المهني. والتدريب على مهارات الحياة الأكثر لمساعدتهم على النجاح. وذلك بالتعاون مع مكاتب التعليم الخاص. وذلك من خلال تأهيل (• • ب طالباً. والتدريب على الوظائف ذات الصلة بهم. والمهارات الاجتماعية التى تساعده على المعايشـة. المهارات الادارية. ومهارات الصحة والمنزل. مهارات الوعى المجتمعي. وذلك لأهمية كل هذه

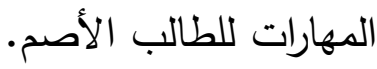
وأكدت دراسة عبد الرحمن (10 • r) التعرف على فعالية تنمية بعض المهارات الحياتية في زيادة دافعية الإنجاز لاى الأطفال الصم. وتكون المجتمع الأصلي لعينة الدراسة من (•r) طفـلاً وطفلـة مـن الأطفال الصم الذين تتراوح أعمارهم بين (1.0 سنوات). وقد أجريت فيها

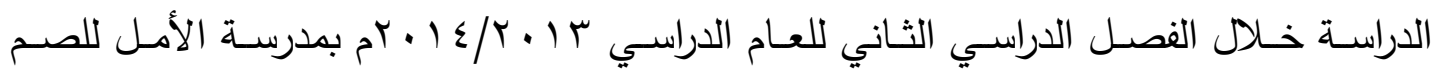
وضـعاف السـمع بمدينـة ملوي التابعـة لدحافظـة المنيـا. أظهرت نتائج الدراسـة فعاليـة برنـامج المهارات الحياتية وجود فروق ذات دلالمة إحصائية بين متوسطي درجات الأطفال الصم في التطبيقين القبلي والبعدي على مقياس المهارات الحياتية المصور لصالح التطبيق البعدي. وحددت دراسـة صديق (10 ب ب) المهارات الحياتيـة وإبعـاد الـافع للإنجـاز المهارات اللازمة للتلميذات الصم وضعاف السمع بالصف الثامن الابتدائي. نتائج الدراسة: وجود فروق 
دالـة إحصـائيا بين متوسطات رتب درجات تلميذات المجموعـة التجريبيـة في التطبيق القبلي والتطبيق البعدي لمستويات الاختبار التحصيلي والاختبار ككل عند مستوى دلالة ه .. . لصالح التطبيق البعدي. ووجود فروق دالة إحصائيا بين متوسطات رتب درجات تلميذات المجموعـة التجربيـة في التطبيق القبلي والتطبيق البعدي لكل مهارة رئيسـة في اختبار المهارات الحياتيـة والاختبار ككل عند مستوى دلالة ه .. . لصالح التطبيق البعدي

ويتضح مما سبق من نتائج البحوث والدراسات السـابقة توصلت الدراسـة الحالية إلى

• أهميـة التدريب على المهارات الحياتيـة وينبغي أن تكـون متواصلة حتى مـا بعد سـن

$$
\text { المراهقة لأهميتها في توجيه وتعليم الصم. }
$$

• أشـارت العديد مـن الدراسـات والبحوث بأهميـة توسيع التدريب على المهارات الحيايتة

وخاصة الحوار لتنمية المحصول اللغوي والمفاهيم اللغوية لدى الصم •

• فعالية الدور الإيجابي وقت التدريب على المهارات الحياتية وإقناع الطلاب الصم بها.

" دور المهارات الحياتية في توجيه الطلاب الصم والبعد عن العنف والتهيئة النفسية. • أثبتت بعض الدراسات أن الطلاب الصم بحاجة كبيرة للمهارات الحياتيـة وتدريههم عليها دوماً ولا يقتصر على السن المبكر فقط.

$$
\text { فـروض الـدراسـة: }
$$

• يوجد فروق بين متوسطي درجات طلاب المجموعة التجريبية. والضابطة في بُعد الاعتماد على النفس في القياس البعدي في اتجاه طلاب المجموعة التجريبية. - يوجد فروق بين متوسطي درجات طلاب المجموعة التجريبية. والضابطة في بُعد التواصل الاجتماعي في القياس البعدي في اتجاه طلاب المجموعة التجريبية. - يوجد فروق بين متوسطي درجات طلاب المجموعة التجربيـة. والضـابطة في بُعد إدارة الوقت في القياس البعدي في اتجاه طلاب المجموعة التجريبية. 
• يوجد فروق بين متوسطي درجات طلاب المجموعة التجريبية. والضابطة في بُعد الحوار في القياس البعدي في اتجاه طلاب المجموعة التجريبية. • يوجد فروق بين متوسطي درجات طلاب المجموعة التجريبية. والضابطة في بُعد الحاسب الآلي في القياس البعدي في اتجاه طلاب المجموعة التجريبية. • يوجد فروق بين متوسطيّ درجات طلاب المجموعة التجريبية. ودرجات طلاب المجموعة الضـابطة في المهارات الحياتيـة في القياس القبلي والبعدي في اتجاه طـلاب المجموعـة

$$
\begin{aligned}
& \text { التجريبية. } \\
& \text { الطـــــــــــــوالإجــراءات } \\
& \text { أولاً: منهـج الـدراســة }
\end{aligned}
$$

المنهج التجريبي: استخدم الباحثان في تجريب البرنامج المقترح على عينة الدراسـة؛ حيث اعتمد على تصميم المجموعتين: المجموعة التجريبية. والمجموعة الضابطة. وذلك للتعرف لبرف على فعالية البرنامج القائم على التعلم الخليط؛ لتتميـة المهارات الحياتيـة لدى الطلاب الصـم

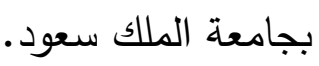
ثانيًا: عينـة الدراسـة

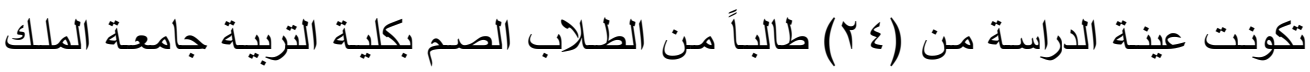
سعود. وذلك هو العدد الملتحق بالجامعة نظرا لحداثة تعليم الصم بالجامعة.

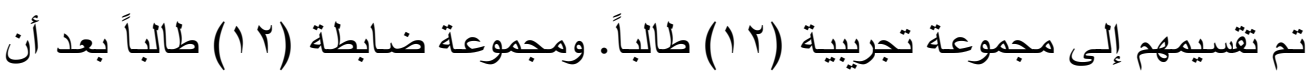
قام الباحث بالتجانس بين المجموعتين.

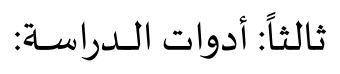

\section{استخدم الباحث الأدوات التالية:}

1 - مقياس المهار ات الحياتية لدى الطلاب الصم بجامعة الملك سعود

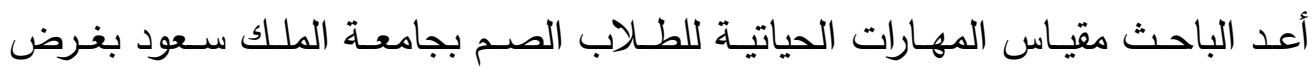
الكثف عن المهارات الحياتية لدي الطلاب الصم بجامعة الملك سعود. وفي ضوء الاطلاع 
على بعض الأدبيات التربويـة الدراسـات السـابقة. تم تحديد أربعـة أبعاد لتضـمينها في مقيـاس المهارات الحياتيـة في الدراسـة الحاليـة. وهـي بُعـد مهارة "الثتقـة بـالنفس. بُعـد مهارة " التواصـل الاجتماعي. بُعد مهارة " الحوار • بُعد مهارة "الحاسب الآلي والإنترنت. صدق البناء للمقياس:

تم التحقق من الاتساق الداخلي للمقياس وذلك بحساب معاملات الارتباط بين درجة كل

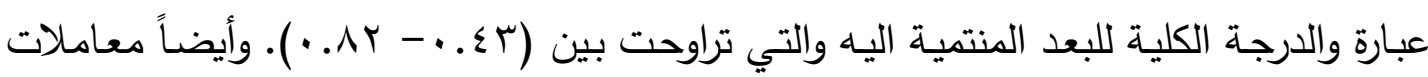
الارتبـاط بين درجـة كل بعد ودرجـات الأبعاد الأخرى للمقيـاس والتي تراوحت بين (VV) . -

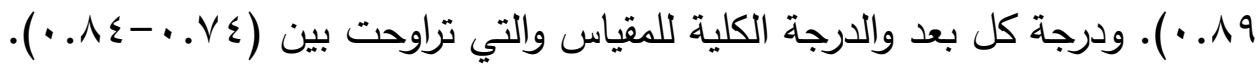
ثبـــــات المق بـــاس: تم التحقق من الثبات وذلك باستخراج معامل الثبات بحساب (م) بطريقة كرونباخ من

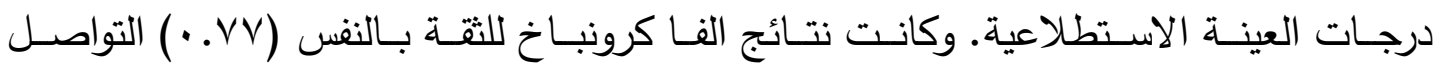

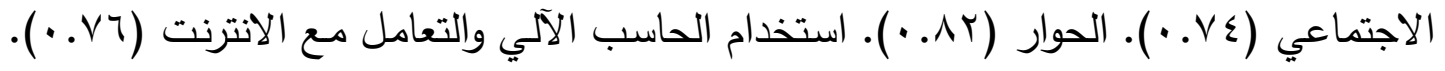
المقياس ككل (r^. • ). وهي نسب مناسبة إحصائياً. مما يدل علي أن مقياس المهارات الحياتية ككل يتميّز بدرجة عالية من الثبات.

\section{الصورة النهائية للمقياس :}

بعـد صـياغة المقيـاس وعرضـهـ على السـادة المحكمـين وضـبطه إحصـائياً ـ أصـبح المقياس في صورته النهائية مكوناً من ( • ب) عبارة ـ موزعة من الأبعاد الأربعة للمقياس كما هو موضح في الجدول التالي:

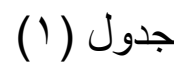

الصورة النهائية لمقياس المهار ات الحياتية

\begin{tabular}{|c|c|c|c|c|c|}
\hline ( & البـحد الرابع & البعد التالت: & البعد التاني & الإنزل & إلإنبال \\
\hline \multirow{2}{*}{7.} & $7 .: \leqslant 7$ & $\varepsilon 0: 1 \Gamma$ & r.:17 & $10: 1$ & أرقام العبارات \\
\hline & 10 & 10 & 10 & 10 & المجموع \\
\hline
\end{tabular}




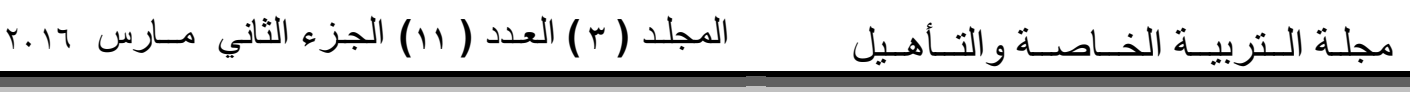

r ـ البرنامج القائم على التعلم الخليط في تتمية المهار ات الحياتية لدى الطلاب الصم بجامعة الملك سعود:

أعد "الباحث" البرنـامج المقترح القـائم على التعلم الخليط فى تتميـة المهارات لتتميـة المهارات الحياتية لدى الطلاب الصم بجامعة الملك سعود. بعد تتاول الخطوات والإجراءات المتبعة في ذلك من حيث ما يلي: تحديد أسس البرنامج المقترح من خلال الاعتماد على بعض المصادر ـ والتواصل مـع إدارة مشروع تعليم الصم وضعاف السمع. وأهداف تعليم الصم وضعاف السمع بجامعة مبحة

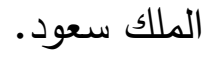

المؤتمرات والندوات التى أقيمت بالمملكة العربية السعودية الورشـة التدريبة" إعداد البنود التنفيذية لمعايير الاتفاقية الدولية لحقوق الاشخاص الإعاقة بجامعات ومؤسسات التعليم

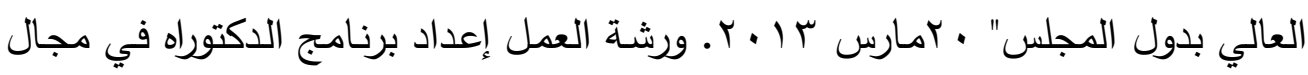

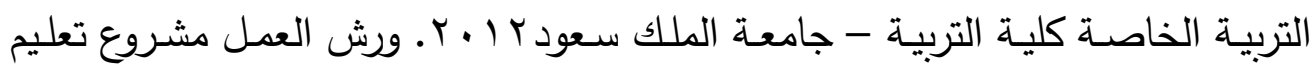

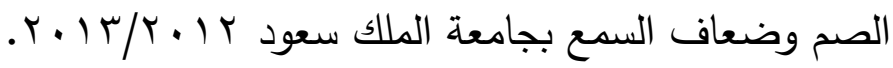

خصائص الصم وضعاف السمع بالمراحل المتقدمة. " تحديد الوسائل التعليمية والأنشطة المستخدمة للمتعلمين الصم. تحديد أساليب التقويم المستخدمة للمتعلمين الصم. مقترحات معدى البرامج والمناهج الدراسية للصم وآليات التواصل معهم.

أهد|ف البرنامج المقترح:

تتميـة المهارات الحياتيـة لـدى الطـلاب بمشـروع تعليم الصـم بجامعـة الملك سـود. ويتضح ذلك من خلال أن يكون الطالب الأصم قادراً على :

تحقيق الاعتماد على نفسه فى شؤون حياته المتقدمة .

• التواصل الاجتماعي مع أفراد مجتمعه ويكون من المؤثرين فى المجتمع · • إدارة وقته بكفاءة واتزان وحسن تتظيم • 
• التحـاور مـع زملانــهـ وجيرانـه ومـن يتعامـل معهم ملتزمـاً بـآداب وأسـس الحـوار

الصحيح.

استخدام الحاسوب فى تعليمه والتعامل مع الإنترنت بكل بجدارة.

• اكتساب مهارات أخرى تصاحب اكتسابه هذه المهارات.

" تمية قدراته ومن ثم توظيفها فيما بعد فى حياته العملية.

بـ الأهداف التعليمية الخاصة بالمهار ات الحياتية:

وفي ضوء هذه الأهداف العامـة يمكن تتمية بعض المهارات الحياتيـة للطـلاب الصـم من

خـلال فعاليـة برنـامج قائم على التعلم الخليط لتتميـة المهارات الحياتيـة لدى الطـلاب الصـــ جامعة الملك سعود.

\section{المحتوى العلمي للبرنامج التقتي المفترح"":}

يأتي هذا البرنـامج المقترح للطـلاب الصـم بمشـرع جامعـة الملك سـود لتعليم الصـم وضـعاف السـمع. ولتحقيق ذلك فإن البرنـامج يتضـن مجموعـة مـن الوحدات التدريسية. وهـى كما يلي: وحدة الثقة بالنفس.

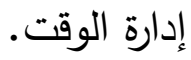

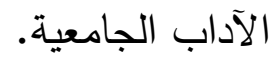

$$
\text { آليات الحوار }
$$

التواصل والتأهيل لسوق العمل.

بالإضـافة إلى بعض الأنشطة التعليميـة والتقويميـة التي يـتم تنفيذها مـع الدارسين مـن خلال ورش العمل المتضمنة في البرنامج المقترح. 
جدول (r)

الجدول الزمني لتدريس وحدات البرنامج

\begin{tabular}{|c|c|c|c|}
\hline البساعات العملية & الساعات النظرية & 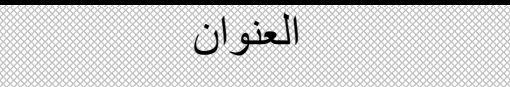 & الوحدة: \\
\hline r & r & الثقة بالنفس & لأول \\
\hline$r$ & r & 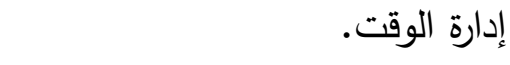 & الثاني \\
\hline$r$ & r & الآداب الجامعية الجية & 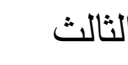 \\
\hline r & r & مفهوم الحوار وآلياته & 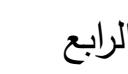 \\
\hline r & r & التواصل والتأهيل لسوق العمل & 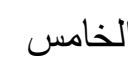 \\
\hline 10 & 10 & \multicolumn{2}{|c|}{ اجمالى عدد اللقاءات التدريبية وورئ العدل } \\
\hline
\end{tabular}

يتضح من جدول رقم (r) زمن تدريس هذا البرنامج المقترح (•r) ساعة تدريسية بواقع

(1 0 ) ساعة نظريـة و(0 1) ساعة عملية. وبواقع ثلاث ساعات نظريـة وثلاث ساعات عملية لكل وحدة تدريسية . تقييم أثر البرنامج تم ذلك من خلال نتائج التطبيقين البعدي وما بعد فترة المتابعة لمقياس تقدير المهارات الحياتية لدي الطلاب الصم (إعداد/ الباحث). الأساليب الإحصائية: - n

تم إجراء التحليل الإحصـائي للبيانات باستخدام الحزمة الإحصـائية للعلوم الاجتماعية Statistical Package for Social Science (SPSS) التاليـة : المتوسطات الحسابية. والانحرافات المعياريـة. وحسـاب معامل الثبات" ألفا كرونبـاخ. اختبار مان وتني. مربع ايتا. 
نتائج الدر /سة . تفسير ها ومناقشتها:

يمكن تلخيص نتائج الدراسة ومناقشتها فيما يلي:

$$
\text { نتـائج الفـرض الأول }
$$

والذى ينص على "يوجد فروق بـين متوسطى درجـات طـلاب المجموعـة التجربيـة.

والضابطة في بُعد الاعتماد على النفس في القياس البعدي في اتجاه طلاب المجموعة التجربية"

جدول (r)

نتائج اختبار مان وتني (Mann Whitney) للفروق بين رتب درجات طلاب المجموعة التجريبية و المجموعة الضّابطة في القياس البعدي لمقياس المهار ات الحيانية (محور الاعتماد

\begin{tabular}{|c|c|c|c|c|c|c|c|c|}
\hline 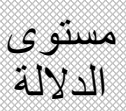 & 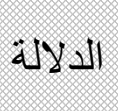 & $\mathbf{z}$ & $\mathbf{U}$ & ع.راز & نونيط & دII II & المجيو عات & المتغير \\
\hline \multirow{2}{*}{ دالة ل } & \multirow{2}{*}{$\cdots \cdot 1$} & \multirow{2}{*}{ r.101 } & \multirow{2}{*}{11} & $r \cdot \varepsilon$ & iv & ir & التجريبية & \multirow{2}{*}{ 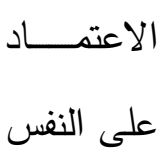 } \\
\hline & & & & 97 & $\wedge$ & ir & الضابطة & \\
\hline \multicolumn{9}{|c|}{$1.97 .=(. .00)$} \\
\hline
\end{tabular}

يتضح من الجدول رقم (r) أن قيمة (z) المحسوبة لمحور الاعتماد على النفس بالنسبة

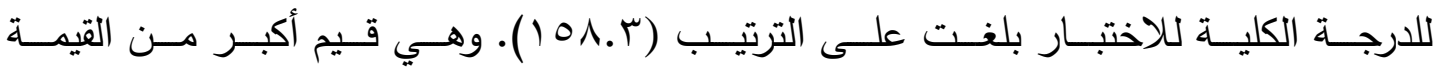

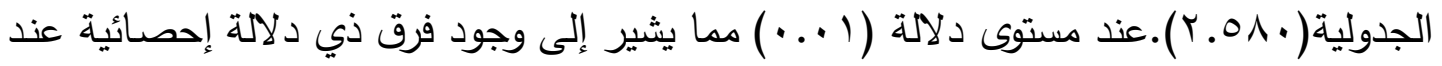
مستوى دلالة ( ( . . ) بين متوسط رتب درجات أفراد المجموعة التجرببية ومتوسط رتب درجات أفراد المجموعـة الضـابطة في القيـاس البعدي لبعـ الاعتمـاد على الـفس لصـالح المجموعـة التجريبية. وهذا يعني ارتفاع درجات أفراد المجموعة التجربيـة وبالتالي تحسنهم وتفاعلهم مـع البرنامج مقارنة بأفراد المجموعة الضـابطة التي لم تتفاعل لنفس البرنامج. مما يشير إلى فعالية البرنامج في تنمية محور الاعتماد على النفس لدى طلاب المجموعة التجريبية. ويمكن تفسير فعالية البرنامج في هذا المحور إلى: مشـاركة وتفاعل الطـلاب. وتتميـة الروح الايجابيـة بين الطـلاب ودخولهم الجامعـة مـع التوجيه والاهتمام. وهذا ما تتقق نتائجه مع دراسة عبد الرحمن (10 ـ ب). ودراسة ديفس

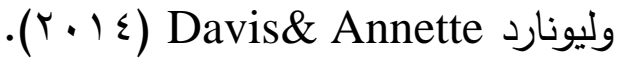


توجيه الطلاب الصم بدون عنت ولا إرهاق إلى الوسائل الإلكترونية المتاحة واعتمادهم على أنفسـهم في تطبيق بمهام محددة وتوجيهـم التوجيـه الصـيح ومراعـاة آليـات التواصل الفعالة معهم يساعدهم على فهم المعلومات والاعتماد على أنفسهم. توفير المصـادر داخل الجامعـة والإنترنت مدا انعكس على تعلمهم واعتمـادهم على لـى أنفسهم. ويتفق ما سبق ودراسة ديفس وليونارد Davis\& Annette (ع ا • (ץ).

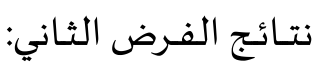
والذي ينص على "يوجد فروق بين متوسطى درجـات طـلاب المجموعـة التجريبيـة والضـابطة في بُعـد التواصـل الاجتمـاعي في القيساس البعدي في اتجـاه طـلاب المجموعـة

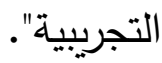

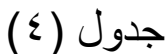

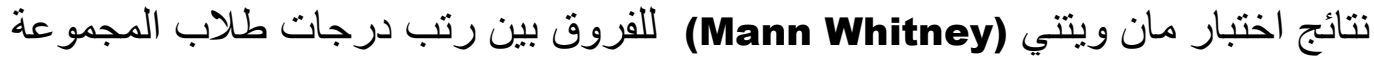
التجريبية والمجموعة الضابطة في المقياس البعدي لمقياس المهار ات الحياتية دئية محور التواصل

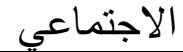

\begin{tabular}{|c|c|c|c|c|c|c|c|c|}
\hline 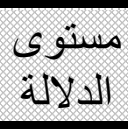 & الدلالة & z & $\mathbf{u}$ & الرنبوع & منوسط & العدد & المجيو عات & المتغير \\
\hline \multirow{2}{*}{ دالة } & \multirow{2}{*}{$\cdots$} & \multirow{2}{*}{ r.Arq } & \multirow{2}{*}{7.0} & r10.0 & 18.97 & IT & التجريبية & \multirow{2}{*}{ الاجتماعي } \\
\hline & & & & $\Lambda \varepsilon .0$ & $V_{.} . \varepsilon$ & Ir & الضابطة & \\
\hline & & & 9 & $. .0)$ & r.01 & . & توى & قيمة (z) ع \\
\hline
\end{tabular}

يتضـح من الجدول رقم (ع) أن قيمـة الحسـوبة لبعد التواصل الاجتمـاعي بالنسبة

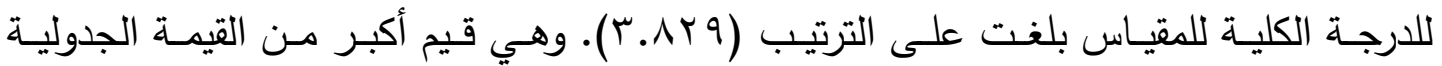

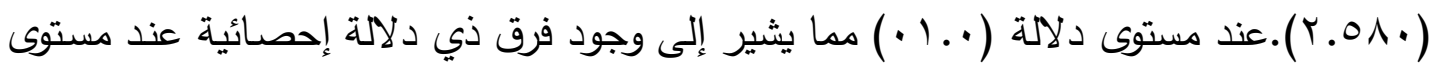
دلالة (. ـ ( ) بين متوسط رتب درجات أفراد المجموعة التجريبية ومتوسط رتب درجات أفراد المجموعة الضابطة في القياس البعدي لبعد التواصل الاجتماعي لصالح المجموعة التجريبية. وهذا يعني ارتفاع درجات أفراد المجموعة التجريبية وبالتي زيادة تفاعلهم مع البرنامج (برنامج 
الدراسـة) مقارنة بأفراد المجموعة الضـابطة التي لم يطبق عليها البرنامج. مما يشير إلى فعالية البرنامج في تنمية بعد التواصل الاجتماعي لاى طلاب المجموعة التجريبية. ويمكن تفسير فعالية البرنامج في هذا المحور إلى:

تعاون الطلاب في ورش العمل مع زملائهم. وحبهم التواصل واشتراكهم في المجموعات بل ادى الى اشتراكهم في مجموعات الواتس آب التوتير • وتبادل الإيميلات مع بعضهم البعض. وتبادلهم اشارات جديدة فيما بينهم ساهم في حبهم للتعرف أكثر. تفاعل الطـلاب الصـم مـع عضو هيئة التدريس أثناء تتفيذ البرنـامج بفاعليـة والتواصل المسـتمر وحبهم للتواصـل عبر وسـائل الإنترنـت ومجموعـات التواصـل. وذلك كمـا

$$
\text { وضحت دراسة صديق (10 • (r). }
$$

تفاعل الطلاب مع عضو هيئة التدريس ومع بعضهم البعض أثناء دراسـة البرنامج أوجد نوعاً من العلاقات الاجتماعية وخاصة في المشاركات فيما بينهم. نتائج الفرض الثالث:

والذى يـص على "يوجد فـروق بـين متوسـطى درجـات طـلاب المجموعـة التجريبيـة

والضابطة في بُعد إدارة الوقت في القياس البعدي في اتجاه طلاب المجموعة التجريبية". جدول (0)

نتائج اختبار مان ويتني (Mann Whitney) للفروق بين رتب درجات طلاب المجموعة التجريبية و المجمو عة الضابطة في القياس البعدي لمقياس المهار ات الحياتية محور إدارة

\begin{tabular}{|c|c|c|c|c|c|c|c|c|}
\hline 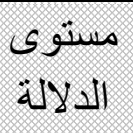 & aty 11 & Z & $\mathbf{U}$ & هجمو ع & مارن & العدد & الd عاتج & المنغير \\
\hline \multirow{2}{*}{ دالة } & \multirow{2}{*}{$\cdots$} & \multirow{2}{*}{$\varepsilon .11$} & \multirow{2}{*}{$\varepsilon$} & Y\A & $11.1 \mathrm{~V}$ & ir & التجريبية & \multirow{2}{*}{ إدارة الوقت } \\
\hline & & & & NY & $\tau . \wedge r$ & Ir & الضابطة & \\
\hline
\end{tabular}

يتضـح مـن الجدول رقم (0) أن قيمـة (z) المحسوبة لبعد إدارة الوقت بالنسبة للدرجـة

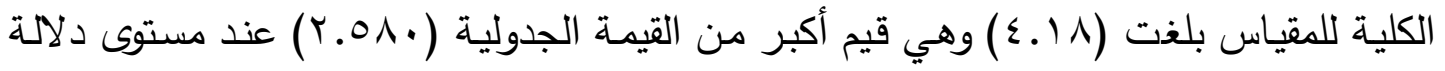


( • ( •) مما يشير إلى وجود فرق ذي دلالة إحصائية عند مستوى دلالة ( . . • ) بين متوسط

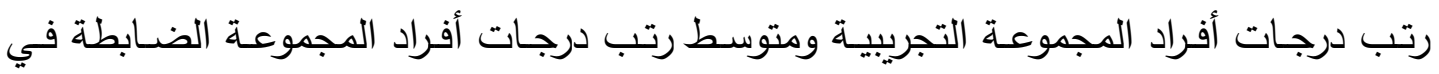
القياس البعدي لبعد إدارة الوقت لصالح المجموعـة التجريبية. وهذا يعني ارتفاع درجات أفراد

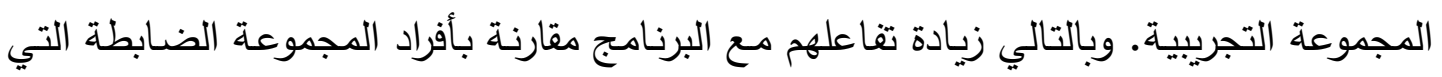

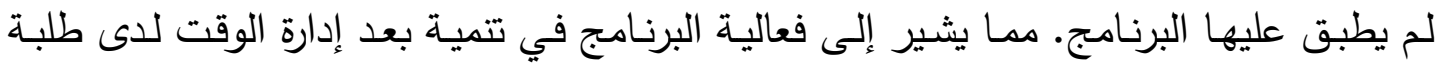

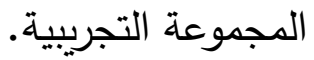

\section{ويمكن تفسير فعالية البرنامج في هذا المحور إلى:}

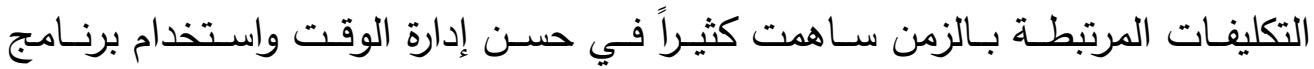
Online Stopwatch من خلال فتحسه على blackboard وتدريب الطلاب الصم عليها ساعد -أيضاً- على تنظيم الوقت وتخصيصه في حل الأنشطة والمشاركة. كما وتداب

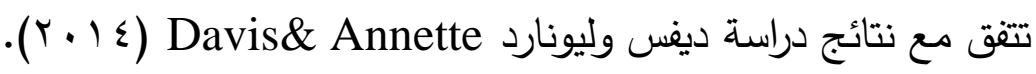
توظيف الطـلاب الصـم لبعض مهاراتهم واتتـانهم لبعض البرامج الكمبيوتر المسـاعدة

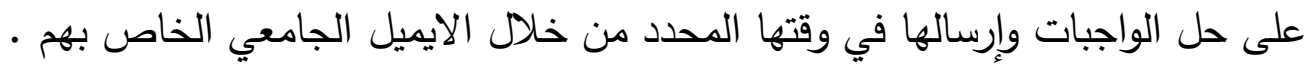

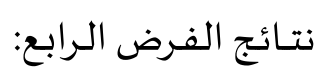

واللذى ينص على يوجـد فروق بـين متوسطى درجـات طـلاب المجموعـة التجريبيـة

والضابطة في بُعد الحوار في القياس البعدي في اتجاه طلاب المجموعة التجريبية.

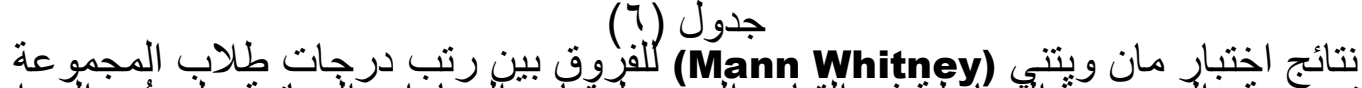

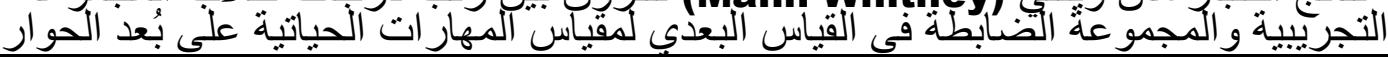

\begin{tabular}{|c|c|c|c|c|c|c|c|c|}
\hline الدلالة & الدلالة & $\mathbf{z}$ & $\mathbf{u}$ & آرنبون & الرّبونب & العدد & المجيكو عات & المنغبر \\
\hline \multirow[b]{2}{*}{ دالة } & \multirow{2}{*}{$\cdots$} & \multirow{2}{*}{ E.11. } & \multirow{2}{*}{1} & TrY & 11.0 & ir & التجريبية & \multirow{2}{*}{ لحوار } \\
\hline & & & & $\vee \wedge$ & 7.0 & Ir & الضابطة & \\
\hline
\end{tabular}

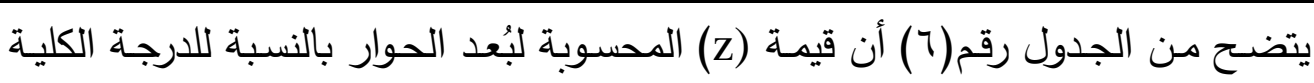

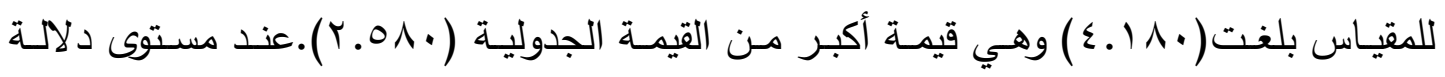
(.. (·) مما يشير إلى وجود فرق ذي دلالة إحصائية عند مستوى دلالة (.. ( ) بين متوسط 
رتب درجـات أفراد المجموعـة التجرببيـة ومتوسط رتب درجـات أفراد المجموعـة الضـابطة في القيـاس البعدي لبُعد الحـوار المجموعـة التجريبيـة. وهذا يعنـي ارتفـاع درجـات أفراد المجموعـة التجريبيـة وبالتالي. تحسنهم وتفـاعلهم مـع البرنـامج مقارنــة بأفراد المجموعـة الضـابطة التي لـم تطبق عليها البرنامج. دما يشير إلى فعالية البرنامج في تنمية بُعد الحوار لدى طلاب المجموعة التجريبية.

\section{ويمكن تفسير فعالية البرنامج في هذا المحور إلى:}

تعبيـر كل طالب ورأيسه وأسـلوب التواصـل الكلى مـع الطـلاب. ومعرفـة عضـو هيئة التـدريس للغــة الإشـارة والتواصـل الكلى سـاهم في الوقت الكـاف للحـوار والمناقشـة. واستخدام الإنترنت.blackboard وعرض بعض الكلمـات الجديدة للطلاب وتتاقلها فيما بينهم. عرض بعض الأمثلة. والمواقف الحياتيـة لكل طالب وتعبيره عن موقفه بوقت كاف ونشاط محدد. ساهم في زيادة المحصول اللغوى وتتمية الحوار بين زملائهـ وعضو هيئة

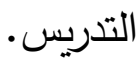
الإيجابية والمشاركة الجماعية من خلال المجموعات المتعاونـة بين الطلاب الصم في ورش العمل. والاسئلة الكثيرة حول أمور كثيرة في الحياة. وآليات التواصل مع الآخرين

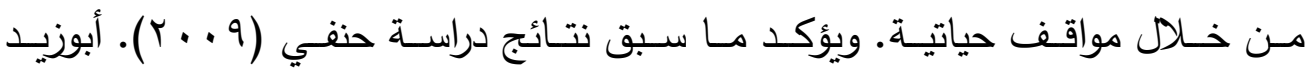

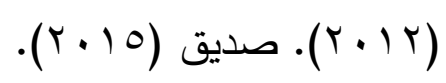
نتـائج الفـرض الخـامس:

والذي يـص على "يوجـ فروق بـين متوسـي درجـات طـلاب المجموعـة التجريبيـة والضابطة في بُعد الحاسب الآلي في القياس البعدي في اتجاه طلاب المجموعة التجريبية". 


$$
\text { جدول (v) }
$$

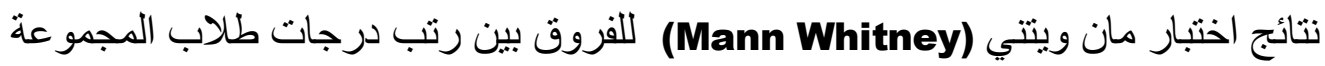

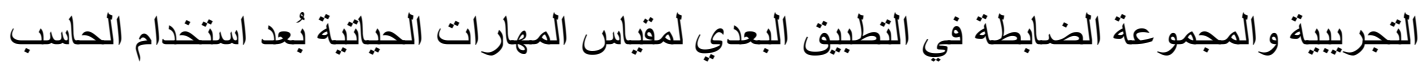

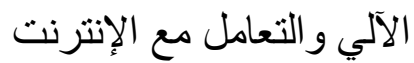

\begin{tabular}{|c|c|c|c|c|c|c|c|c|}
\hline مستوى الدلان & الدلالة & z & $\mathbf{u}$ & نهمبوع & منونبط & العدد & المجيو عات & ال النغير \\
\hline \multirow[b]{2}{*}{ 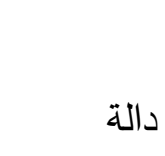 } & \multirow{2}{*}{$\cdots r$} & \multirow{2}{*}{$\cdot r \varepsilon . r$} & \multirow{2}{*}{$\Gamma \varepsilon$} & 114 & $10.7 \mathrm{~V}$ & ir & التجربيية & \multirow{2}{*}{ الآلكي } \\
\hline & & & & $11 r$ & T.r & ir & الضابطة & \\
\hline & & \multicolumn{3}{|c|}{$1.97 .=(\cdot . .0)$} & \multicolumn{4}{|c|}{ 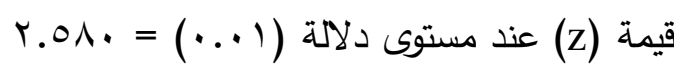 } \\
\hline
\end{tabular}

يتضح من الجدول رقم (V) أن قيمة (z) الدحسوبة لبُعد الحاسب الآلي بالنسبة للدرجة

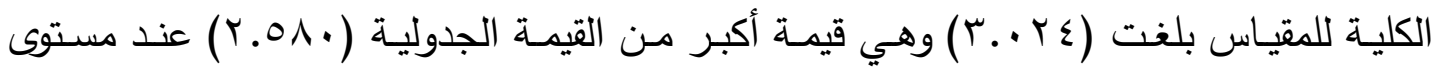
دلالة (. . • ) مما يشير إلى وجود فرق ذي دلالة إحصائية عند مستوى دلالة (.. ( ·) بين متوسط رتب درجات أفراد المجموعة التجريبية ومتوسط رتب درجات أفراد المجموعة الضابطة في القياس البعدي لمحور الحاسب الآلي المجموعة التجريبية. وهذا يعني ارتفاع درجات أفراد

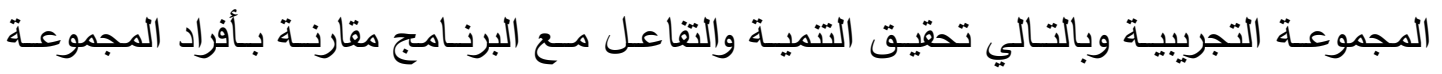
الضـابطة التي لم تتفاعل مع البرنامج .مما يشير إلى فعالية البرنامج في تتمية بعد الحاسب الآلي للدى طلاب المجموعة التجريبية.

\section{ويمكن تفسير فعالية البرنامج في هذا المحور إلى:}

توفير الجامعة أجهزة الحاسب الآلي داخل القاعات التدريسية. "إيجابية الطلاب الصم نحو الحاسب الآلي. مثل: محركات البحث. والمناقشات الصفية. ومنتّى الحوار الخاصة بالصم. توفير الانترنت من خلال الجامعة. والباقات على التليفون الدحمول " الجوال" ساهم في حب التواصل بين الطلاب. وتوفير الوقت. 
توجيه الطـلاب الصم لحل الواجبات باستخدام الحاسب الآلي وإكسابهح مهارات إنشـاء

الملفات والحفظ والتحميل والتحرك بالموقع الإككتروني. مما نمى لديهم هذه المهارة. توجيـه الطـلاب لاسـتخدام الكيبـورد باللغـة العربيـة؛ لتعـرف الكتابـة. والكلمـات. وتنزيـل برنـامج الخطوط الخاصـة بالصـ deaf fonts سـاعدهم على التعرف على مكونـات أخرى للكمبيوتر • وتتفق النتائج السـابقة مـع نتائج بعض الدراسـات التي اهتمـت بـذلك

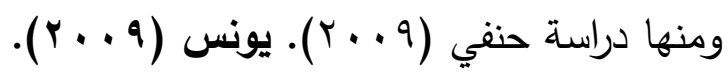

$$
\text { نتائج الفرض السادس: }
$$

والذي ينص على " يوجد فروق بـين متوسطيّ درجـات طـلاب المجموعـة التجربيـة ودرجات طلاب المجموعة الضابطة في المهارات الحياتية في القياس القبلي والبعدي في اتجاه طلاب المجموعة التجريبية". والجدول التالي يوضح ذلك: جدول(^)

نتائج اختبار مان ويتني (Mann Whitney) للفروق بين رتب درجات طلاب المجمو عة

\begin{tabular}{|c|c|c|c|c|c|c|c|c|}
\hline 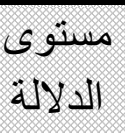 & الإل & $\mathbf{z}$ & $\mathbf{u}$ & هجبوع & 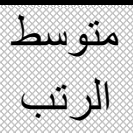 & 7all & المجيو عات. & المنغير \\
\hline \multirow{2}{*}{ دالة ل } & \multirow{2}{*}{$\cdots \cdots$} & \multirow{2}{*}{$.0 V . \varepsilon$} & \multirow{2}{*}{$r$} & rr. & IA.r & IT & التجريبية & مقيـاس المهـارات \\
\hline & & & & ᄉ. & $7.7 \mathrm{~V}$ & ir & الضابطة & الحياتية ككل \\
\hline \multicolumn{9}{|c|}{$1.97 .=(. .00)$} \\
\hline
\end{tabular}
التجريبية و المجمو عة الضابطة في التطبيق القبلي و البعدي للاختبار ككل لبن لتبن

يتضح من الجدول رقم (^) أن قيمة (z) المحسوبة للاختبار ككل بالنسبة للدرجة الكلية

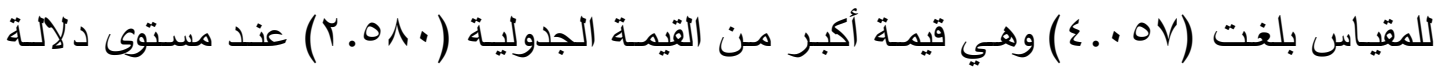
( • ( • ) مما يشير إلى وجود فرق ذي دلالة إحصائية عند مستوى دلالة ( . ( • ) بين متوسط رتب درجـات أفراد المجموعـة التجريبيـة ومتوسط رتب درجـات أفراد المجموعـة الضـابطة في القيـاس القبلي والبعـدي للمقيـاس ككل المجموعـة التجريبيـة. وهذا يعنـي ارتفـاع درجـات أفراد المجموعـة التجريبية وبالتالي تحسنهم وتفاعلهم مـع البرنـامج مقارنـة بأفراد المجموعـة الضـابطة 
التي لم تطبق عليها البرنـامج مما يشير إلى فعالية البرنـامج في تتميـة المهارات الحيايتة لدى طلاب المجموعة التجريبية.

\section{ويمكن تفسير فعالية البرنامج في هذا المحور إلى:}

طبيعـة مدخل عملية التعلم الخليط. ومشـاركة الطـلاب الفعالة في الأنشطة. وتبادلهم

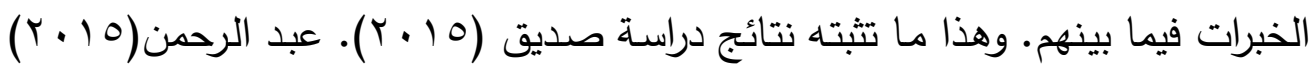

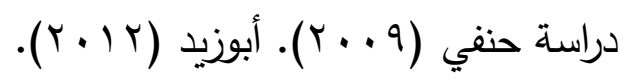

توفير مصادر التعلم. والانترنت داخل الجامعة. ومشاركة الطلاب في وش العمل. إجادة عضو هيئة التدريس بالتواصل مـع الطلاب بأساليب التواصل الكلي. ومساعدتهم على بناء الثقة لديهم. حيث وصولهم للمرحلة الجامعيـة دافع للتعلم. وإكسابهم مهارات جديدة. وحبهم للتواصل والمعرفة.

\section{جدول(9) (9)}

نتائج اختبار ويلكوكسون للفروق بين درجات التطبيقين القبلي و البعدي على مقياس المهار ات الحياتية و أبعاده الفر عية لدى طلاب لئ المجمو عة التجريبية

\begin{tabular}{|c|c|c|c|c|c|c|c|c|c|}
\hline التأثبر & 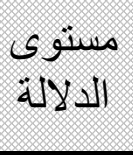 & avy & z & |ر & الرنبط. & | & ij & القيانس & 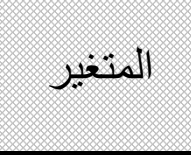 \\
\hline \multirow{3}{*}{$r \cdot, q \leq$} & \multirow{3}{*}{ دالة } & \multirow{3}{*}{$\cdot, \cdots r$} & \multirow{3}{*}{$r . . T V$} & - & . & - & الموجبة & \multirow{3}{*}{ البعدي } & \multirow{3}{*}{ الاعتمساد على } \\
\hline & & & & \multirow{2}{*}{$\vee \wedge$} & \multirow{2}{*}{7.0} & ir & السالبة & & \\
\hline & & & & & & . & المتساوية & & \\
\hline \multirow{3}{*}{$r \cdot, 9 \leqslant$} & \multirow{3}{*}{ دالة } & \multirow{3}{*}{$\cdot, \cdots r$} & \multirow{3}{*}{$r . . T V$} & . & . & - & الموجبة & \multirow{3}{*}{ البعدي القبلــــــ } & \multirow{3}{*}{ الاجتماعي } \\
\hline & & & & \multirow{2}{*}{ VA } & \multirow{2}{*}{7.0} & ir & السالبة & & \\
\hline & & & & & & • & المتساوية & & \\
\hline \multirow{3}{*}{$r \cdot, q \leq$} & \multirow{3}{*}{ دالة } & \multirow{3}{*}{$\cdot, \cdots r$} & \multirow{3}{*}{$r . . \wedge V$} & . & . & . & الموجبة & \multirow{3}{*}{ البعدي القبلــــــ } & \multirow{3}{*}{ إدارة الوقت } \\
\hline & & & & \multirow{2}{*}{$\vee \wedge$} & \multirow{2}{*}{7.0} & ir & السالبة & & \\
\hline & & & & & & - & المتساوية & & \\
\hline \multirow{2}{*}{$r \cdot, q \varepsilon$} & \multirow{2}{*}{ دالة } & \multirow[b]{2}{*}{$\cdot, \cdot r$} & \multirow{2}{*}{$r . . v \wedge$} & . & . & . & الموجبة & \multirow{2}{*}{ 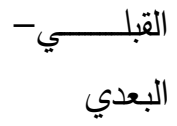 } & \multirow[b]{2}{*}{ الحوار } \\
\hline & & & & $\vee \wedge$ & 7.0 & Ir & السالبة & & \\
\hline
\end{tabular}




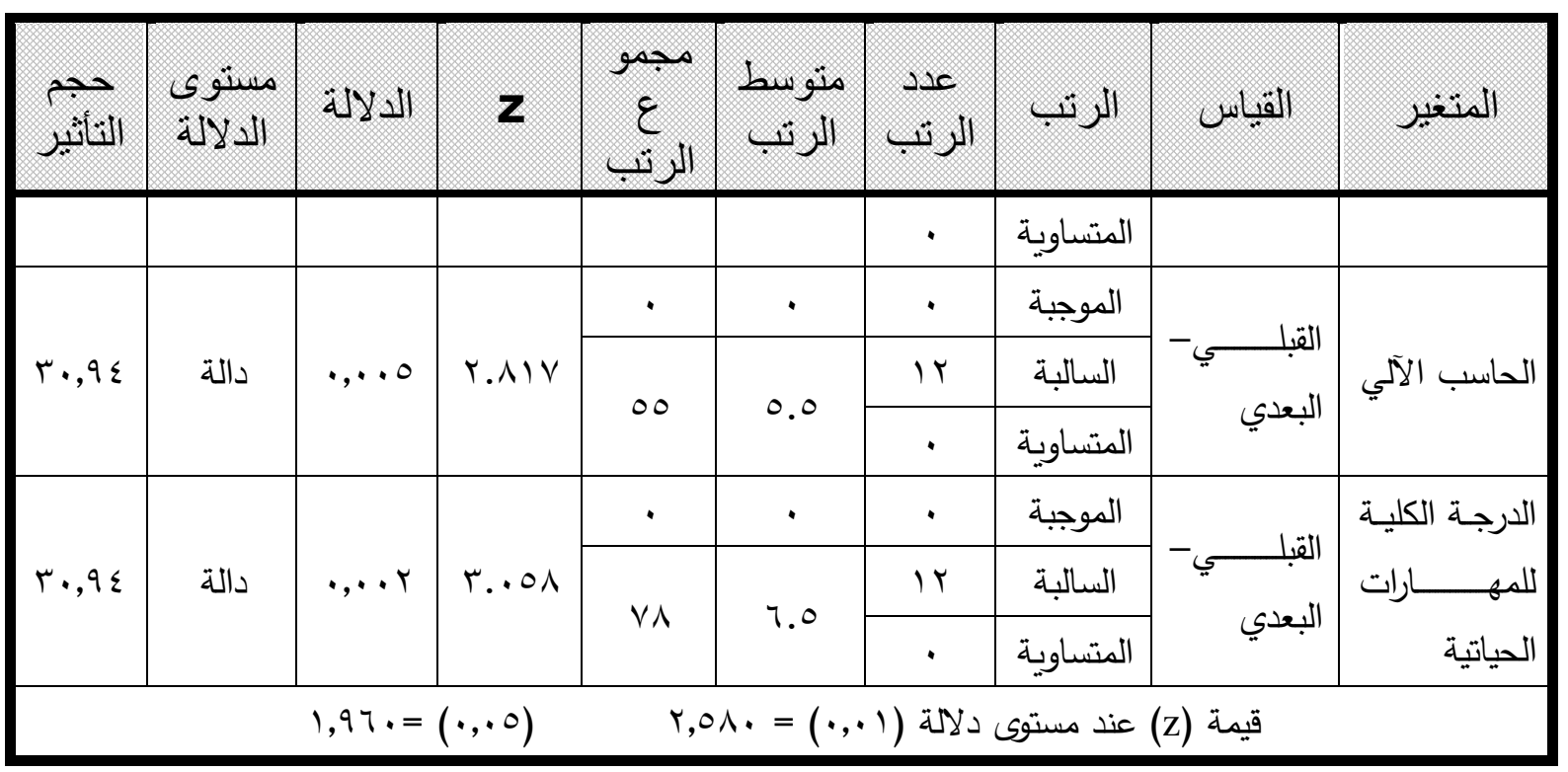

يتضح من الجدول رقم ( ع-ـ ()أن قيمة (z)المحسوبة لأبعاد مقياس المهارات الحياتية

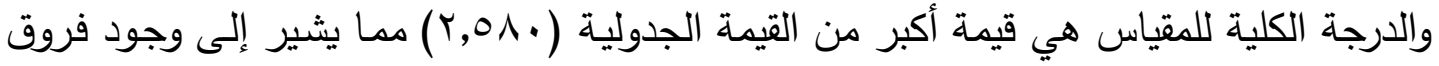

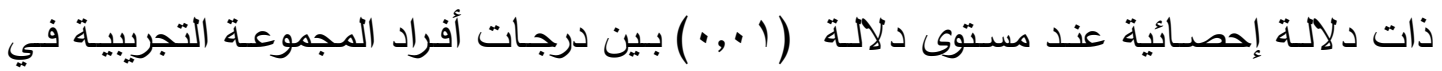
القياسين القبلي والبعدي للمهارات الحياتية لصالح القياس البعدي. مما يشير إلى أن البرنامج كان ذا فاعلية وتأثير قوي في تتمية المهارات الحياتيـة لدي طلاب العينة. أو المجموعة التجريبية في جميع جوانب المقياس الفرعية " الاعتماد على النفس التواصل الاجتماعي. إدارة الوقت. الحوار . الحاسب الآلي" كما أن نتائج القياس القبلي والبعدي لأبعاد مقياس المهارات الحياتية ككل وكل بعد من أبعاده على حده جاءت معبرة عن مدى تفوق طلاب المجموعة التجريبية التي درست بالبرنامج المقترح • ويمكن تفسير النتائج السابقة إلى ما يلي:

تصميم البرنامج وفق احتياجات وخصائص الطلاب الصم في البيئية الجامعية. اعتمـاد البرنـامج على الدراسـات الحديثة والتجـارب الناجحة ويتفق هذا مـا بعض نتائج الدراسـات السـابقة ومنهـا دراسـة حنفي (9 . . ب) التـي نـادت بأهميـة دور التكنولوجيـا المسـاندة ودورها في تفعيـل أهداف تعليم ذوي الإعاقـة السمعية. ودراسـة إبراهيم يونس

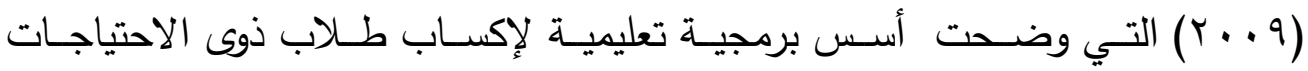
الخاصـة( المعاقين سمعياً) وأثر ذلك على تواصلهم غير اللفظي مـع الآخرين. دراسـة الغرباوي(0 ( م ب) التي سـاهمت ببرنـامج قائم على التعليم المدمج في تتميـة المهارات 
Ketelaar. et.. al al الحياتيـة وتقدير الذات للدى الطـلاب الصـم. كيتلار وآخرون

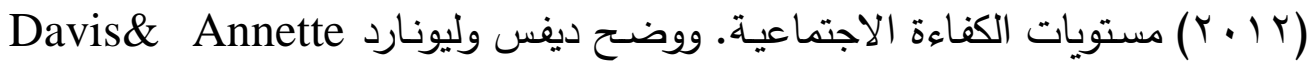

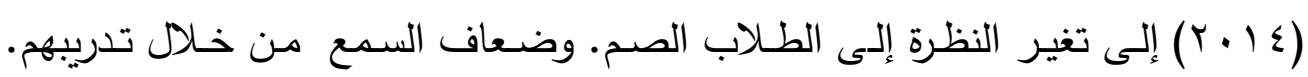

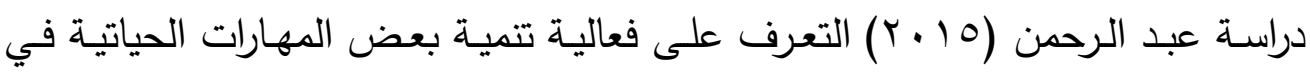

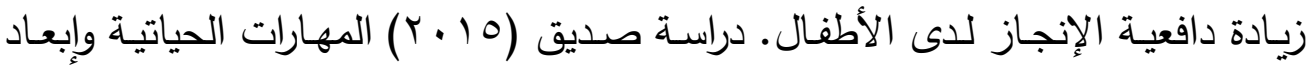

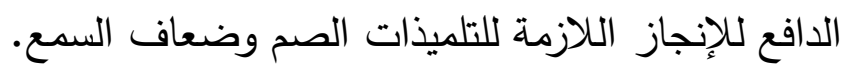
وللتعرف على قوة تأثير البرنامج استخدم الباحثان معامل الارتباط الثنائي الذي اقترحهـ "جلاس"؛ حيث يقوم بحساب قوة الارتباط بين المتغير التابع. وهو المهارات الحياتية وأبعادها. والمتغير المستقل (عبد المنعم. 0. . ب. .0. 1).

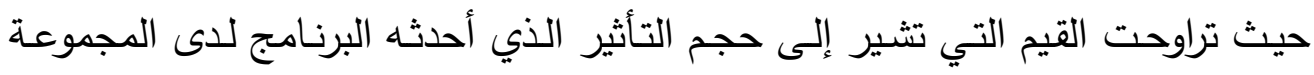

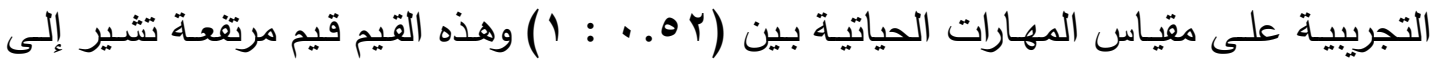
فعالية البرنامج في تتمية المهارات الحياتية المستخدمة في هذا الدراسـة. وكذلك الدرجة الكلية

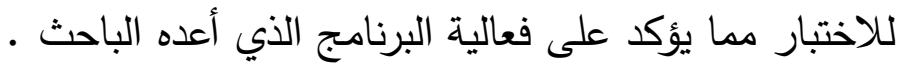

$$
\text { تـوصيـات الــر/ســة : }
$$

في ضوه ما توصل اليه الدراسة من نتائج يوصي الباحثان بما يلي:

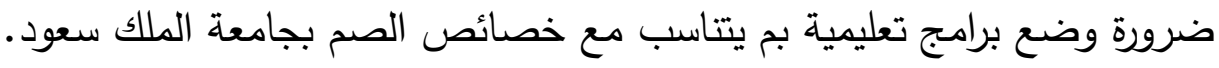
توظيف المهارات الحياتية بشكل فعال داخل الجامعة وخارجها.

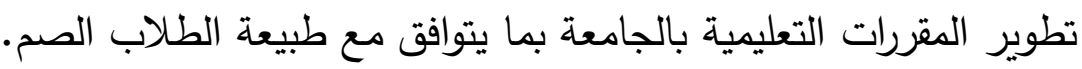
عمل مقياس لتنمية المهارات الحياتية. بما يتناسب مع البيئة بالممكلة العربية السعودية لفولفية

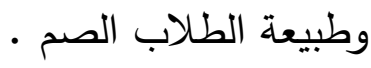
مقترحات الدر/سة: - مانة

فعالية برنامج مقترح لتتمية مهارات الحوار لدى الطلاب الصم بجامعة الملك سعود. فعالية برنامج مقترح قائم على مهارات التواصل غير اللفظي لتمية مهارات التككير الإبداعي. 


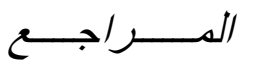

أبوزيد. أحمد؛ وحسن. ياسر (r ( †). مدي فاعلية التدريب علي المهارات الاجتماعية في خفض بعض الاضطرابات السلوكية والوجدانية لدي الأطفال الصم. مجلة

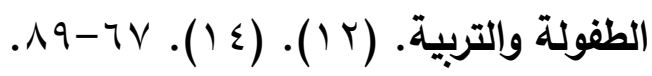

أحمد. اسلام جابر (9 . . r). تصميم برنامج كمبيوتر وقياس فاعليته في تنمية المهارات والاتجاهات نحو استخدام الانترنت لدى التلاميذ المعاقين سمعياً. مجلة كلية

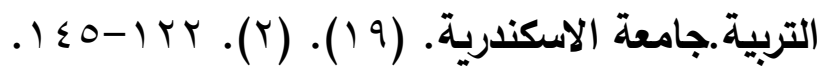

حنفي. على عبد رب النبي (9 . . r) مدخل إلى الإعاقة السمعية. المؤتمر الدولي السابع • القاهرة: معهد الدراسات التربوية بجامعة القاهرة.

الريس. طارق (ع ا • r). نجاحات الصم في التعليم العالي وإنجازاتهم قصص واقعية. موقع دكتور

$$
\text { طارق الرس }
$$

http://faculty.ksu.edu.sa/10361/DocLib4/Forms/AllItems.aspx زائد. هند يوسف محمد (10 (10). فاعلية برنامج مقترح قائم على استخدام التعلم الخليط لتنمية مهارات التفكير التاريخي والتواصل الاجتماعي لاى طالبات الصف

$$
\text { الأول الثانوي • رسالة دكتوراه. كلية التربية. جامعة عين شمس. }
$$

سلامة. حسن (0 . . ب). التعلم الخليط التطور الطبيعي للتعلم الالكتروني. مجلة كلية التربية

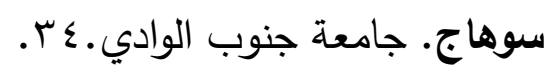

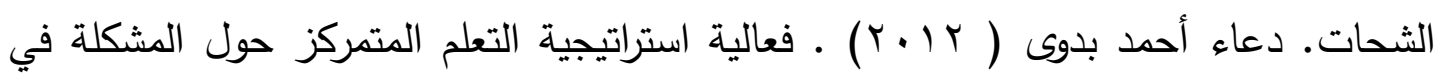
تنمية بعض المهارات الحياتية في مادة العلوم لدي تلاميذ الصف الخامس

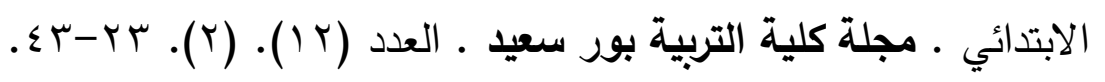

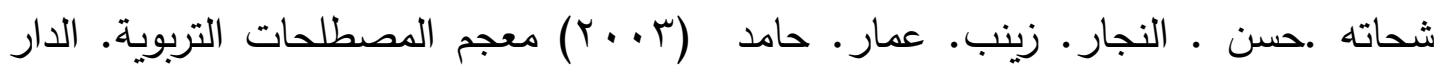

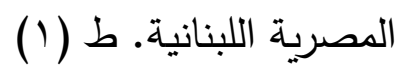

شوملي. قسطندي (V) . . r): الأنماط الحديثة في التعليم العالي التعليم الاكتروني المتعدد الوسائط أو التعليم المتمازج. المؤتمر الساد لعمداء كليات الآداب في الجامعات الأعضاء في اتحاد الجامعات العربية. ندوة ضمان جودة التعليم

$$
\text { والاعتماد الأكاديمي. جامعة الجنان. جامعة بيت لحم. نيسان. }
$$


صديق, مروة سيد فتحي (10 · ب). فاعلية برنامج مقترح قائم على المدخل البصري المكاني في تدريس العلوم للتلاميذ بمدارس الصم وضعاف السمع على التحصيل وتنمية المهارات الحياتية وإلافع للإنجاز. رسالة دكتوراه. كلية التربية. جامعة الفيوم.

الصقير • إبراهيم صقير سليمان (1) (1). أثر استخدام برنامج وسائل متعددة في تنمية بعض مفاهيم الجغرافيا لاى التلاميذ الصم بالمرحلة المتوسطة بالمملكة العربية السعودية. رسالة ماجستير • كلية التربية جامعة عين شمس: القاهرة. عبد العاطي. حسن الباتع؛ والسيد. عبد المولى (1 . . r). أثر استخدام كل من التعلم الإكتروني والتعلم المدمج في تنمية مهارات تصميم وإنتاج مواقع الويب التعليمية لاى طلاب الدبلوم المهنية واتجاهاتهم نحو تكنولوجيا التعلم الإكتروني. تكنولوجيا التربية: دراسات وبحوث. تم استرجاعه في http://www.ahmedasr.com عبد المولا. أسامة عبدالرحمن محمد (· (ب). فاعلية برنامج قائم على البنائية الاجتماعية باستخدام التعلم الخليط في تدريس الدراسات الاجتماعية على تنمية المفاهيم الجغرافية والتفكير البصري والمهارات الحياتية لدى التلاميذ الصم بالحلقة الاعدادية. رسالة دكتوراه. كلية التربية. جامعة سوهاج: القاهرة. عبدالرحمن. نعمة إبراهيم عبدالغفار (10 • ب). فعالية برنامج مقترح في تنمية بعض المهارات الحياتية لزيادة دافعية الإنجاز لاى الأطفال الصم. رسالة ماجستير. كلية التربية. قسم تربية الطفل. جامعة المنيا.

العجب. محمد (r.r.r. إبريل). دور تقنية التعلم الإكتروني في تحقيق أهداف التعلم المفتوح. ورقة عمل مقدمة لندوة التعلم الإكتروني. مدارس الملك فيصل:

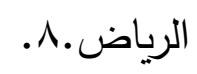


عمران حسن حسن.( • ( • . يناير ).أثر برنامج قائم على معايير اللغة العربية في تتمية المهارات الحياتية اللازمة لطلاب المرحلة الثانوية. مجلة كلية التربية. المجلد

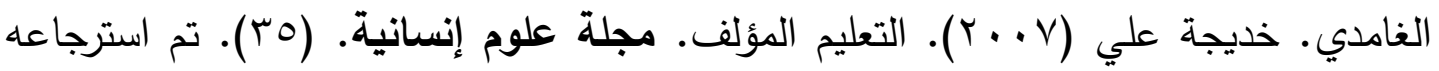

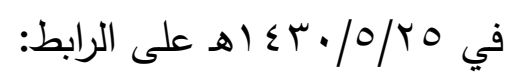

http://www.ulum.nl/c108.html

الغرباوي. سراء محمد السيد(10 · ب) فاعلية برنامج قائم على التعليم المدمج في تنمية المهارات الحياتية وتقدير الذات لاى الطلاب الصم والبكم. رسالة دكتوراه. كلية

الاقتصاد المنزلي. قسم الاقتصاد المنزلي. جامعة المنوفية.

مجاهد, ولاء احمد مختار محمد (10 ب (1). أثر فعالية الذات والمساندة الاجتماعية على بعض المهارات الحياتية لاى عينة من طلاب الجامعة. رسالة دكتوراه. كلية الآداب.

$$
\text { قسم علم النفس. جامعة الإسكندرية. }
$$

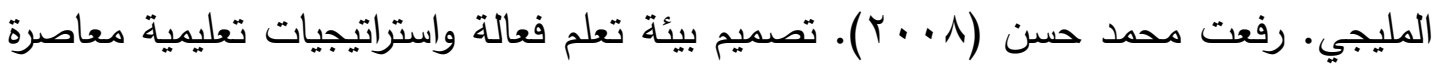
للتلاميذ ذوي الإعاقات السمعية والبصرية ـ مجلة كلية التربية. (ع). (1). $.1 T \varepsilon-11 T$

الموسي. عبد الله عبد العزيز (r . . ץ). التعليم الإكتروني. مفهومه. خصائصه. فوائده. عوائقه . ورقة عمل مقدمة إلي ندوة مدرسة المستقبل بجامعة الملك سعود. متاح علي الموقع التالي وزارة التربية والتعليم.(rv \& ا هـ). دليل مفاهيم الإثراف التربوي. الرياض. • r. يونس • ابراهيم (9 . . r). فاعلية برمجية تعليمية لإكساب طلاب ذوى الاحتياجات الخاصة (المعاقين سمعياً) بعض مهارات تصميم العروض التقديمية وأثر ذلك على تواصلهم غير اللفظي مع الآخرين. مجلة كلية التربية جامعة الأزهر . (Tء (). 
Abraham. A. (2007). Adopting a student-centred pedagogy in the teaching of accounting to engineering students: Comparing a blended learning approach with a traditional approach. In ICT: Providing choices for learners and learning. Proceedings ascilite Singapore

Angeroth. C. (2009): transition program pays of fiowa students learn to search for. find. and keep jobs. Journal New Directions in Deaf Education. 10 . 1 . 27-30.

Davis. C; \& Leonard. A. (2007): A Key to Evaluation: The Transition Competence Battery for Deaf Adolescents and Young Adults. Journa.1 New Directions in Deaf Education .8 . .6-9. ERIC Number: EJ903155

Gray. Caroline(2006):Blended Learning: Why Everything Old Is New Again-But Bette http://www.learningcircuits.org/2006/March/gray.htm

Ketelaar. L.. Rieffe C.. Wiefferink. C.. \& Frijns. M. (2012): Social Competence and Empathy in Yong Chihd with Cochlear Implants and with Normal Hearing. Th laryngoscope. Doi:10.1002/lary.23544

Larson. k; \& Sung. C. (2009).Comparing Student Performnce; Online versus Blended versus Face to face. Reports-Research.(ERIC No: ED 837556).

Maghsoudi. J.(2010) " The effect of acquiring life skills through humor on social adjustment rate of the female students" Iran J Nurs Midwifery Res .v.15(4); Autumn 2010 .PMC3203276 
Ross. S.. \& Cassy. J. (2000). Using interactive software to develop students' problem - solving skills: evaluation of 'Intelligent physics Tutor'. Reports-Evaluative. (ERIC No: ED 373754).

Rossett .A.. Douglis. F.. \& Frazee. V. (2005) Strategies for Building Blended learning . Learning Circuits .(File ://F:strategies \%20for Building \%20 Blended \%20learning.htm)

Yoon. W.. \& Lim. H. (2007). Strategic Blending: A Conceptual Framework to Improve Learning and Performance. International Journal on E-Learning. 6 .3. 475-489. 